\title{
Numerical simulation on solid-liquid two-phase flow in cross fractures
}

\author{
Peng $\mathrm{Li}^{\mathrm{a}, \mathrm{b}}$, Xuhui Zhang ${ }^{\mathrm{a}, \mathrm{b}, *}$, Xiaobing $\mathrm{Lu}^{\mathrm{a}, \mathrm{b}}$ \\ ${ }^{a}$ Institute of Mechanics, Chinese Academy of Sciences, Beijing 100190, China \\ ${ }^{\mathrm{b}}$ School of Engineering Science, University of Chinese Academy of Sciences, Beijing 100049, China
}

\section{H I G H L I G H T S}

- The dimensionless controlling parameters were derived to describe the particle-laden flow in cross fractures.

- Two-Fluid Model closed by the kinetic theory of granular flow was adopted to describe the solid-liquid flow.

- Larger bypass angle between the main slot and branch slot leads to less particle's flow into the branch slot.

- A new dimensionless number $\Pi$ can describe the ratio of the liquid's carrying capacity to the particles' sedimentation effect.

\section{A R T I C L E I N F O}

\section{Article history:}

Received 16 September 2017

Received in revised form 8 January 2018

Accepted 3 February 2018

Available online 6 February 2018

\section{Keywords:}

Cross fracture

Two-fluid model

Two-phase flow

Fracture width

Angle

\begin{abstract}
A B S T R A C T
This paper presents a series of numerical simulation on solid-liquid two-phase flow in cross fractures based on the Two-Fluid Model and the kinetic theory of granular flow (KTGF). First, the model is validated by previous experimental data. Second, the dimensionless controlling parameters are derived to describe the particle-laden flow in cross fractures, including the angle between the main and branch slots (bypass angle) $\theta$, inlet particle volume fraction $\alpha_{s 0}$, the ratio of particle size to branch slot width $d_{s} / w_{b}$, the Archimedes number Ar and the Reynolds number Re. Third, the effects of the dimensionless parameters are investigated. The results show that particles tend to accumulate at the intersection between the main slot and the branch slot. Larger bypass angle between the main slot and branch slot leads to less particle's flow into the branch slot. The distance of the branch fracture from the inlet of the main fracture induces different particle-flow characteristics into the branch slot. Particle volume fraction at the stable stage increases with the decrease of $d_{s} / w_{b}$. The deposition thickness of particles increases with the increase of the inlet volume fraction and $A r$ number, while decreases with the increase of Re number.
\end{abstract}

(c) 2018 Elsevier Ltd. All rights reserved.

\section{Introduction}

Hydraulic fracturing is a common method to form connected fracture networks in the tight oil or gas reservoirs by injecting high speed and high pressure fluid. Accompanied with the hydraulic fracturing process, proppants are carried into the fractures. Well distributed proppants throughout the fracture network are capable of keeping the cross fracture network open and increasing the flow conductivity. The distribution range of the proppant is of great importance to keep the flow conductivity in the complex fractures (Tsai et al., 2012).

Previous researches have been conducted to understand the flow behavior of the proppant-laden fluid in a single vertical fracture. A slot made by two Plexiglas plates was firstly used by Kern

\footnotetext{
* Corresponding author at: Institute of Mechanics, Chinese Academy of Sciences, Beijing 100190, China.

E-mail address: zhangxuhui@imech.ac.cn (X. Zhang).
}

et al. (1959) and subsequently improved by Babcock et al. (1967) to simulate sand deposition and transportation in a vertical planar fracture. The sand settles down and forms a stable dune at the bottom of slot due to the density of sand is larger than that of water when the mixture of sand and water is injected into the fracture slot (shown in Fig. 1). The height of the sand dune increases progressively to a steady state. The increase in the height of the sand dune reduces the flow area of fracture's cross section and, accordingly increases the velocity of proppant-laden fluid. When the sand bed and the fluid velocity reaches a dynamic equilibrium, the height of the sand is called "equilibrium height", and the velocity is called "equilibrium velocity" (Babcock et al., 1967). Similar phenomenon and physical processes were observed in experiments by Wang et al. (2003) and Sahai et al. (2014).

Recently, several studies on the proppant transport in the complex fracture networks were conducted. Sahai et al. (2014) fabricated a lab scale experimental apparatus with four different slot configurations to simulate proppant flow from the primary to 


\begin{tabular}{|c|c|c|c|}
\hline \multicolumn{4}{|c|}{ Nomenclature } \\
\hline$C_{D}$ & drag coefficient & $\delta$ & voidage \\
\hline$d_{\mathrm{s}}$ & particle diameter $(\mathrm{m})$ & $\varepsilon$ & dissipation rate of turbulent kinetic energy $\left(\mathrm{m}^{2} \mathrm{~s}^{-3}\right)$ \\
\hline$D_{i j}$ & strain tensor for solid phase $\left(\mathrm{s}^{-1}\right)$ & $\theta$ & angle \\
\hline$D_{\mathrm{H}}$ & hydraulic diameter $(\mathrm{m})$ & $\Theta$ & granular temperature $\left(\mathrm{m}^{2} \mathrm{~s}^{-2}\right)$ \\
\hline$e$ & coefficient of restitution & I & stress tensor \\
\hline $\mathrm{Fr}$ & Froude number & $\mathrm{I}_{2 D}$ & second invariant of the deviatoric stress tensor \\
\hline$g$ & gravitational acceleration $\left(\mathrm{m} \mathrm{s}^{-2}\right)$ & $\lambda$ & bulk viscosity (Pa s) \\
\hline$g_{0}$ & radial distribution coefficient & $\mu$ & shear viscosity (Pa s) \\
\hline$G_{k}$ & generation of turbulent kinetic energy $\left(\mathrm{kg} \mathrm{m}^{-1} \mathrm{~s}^{-3}\right)$ & $\xi$ & specularity coefficient \\
\hline$H$ & height $(\mathrm{m})$ & $\Pi$ & the ratio of the Reynolds number and the Archimedes \\
\hline I & turbulence intensity & & number \\
\hline$k$ & turbulence kinetic energy $\left(\mathrm{m}^{2} \mathrm{~s}^{-2}\right)$ & $\rho$ & density $\left(\mathrm{kg} \mathrm{m}^{-3}\right)$ \\
\hline$k_{\Theta_{\mathrm{s}}}$ & diffusion coefficient for granular energy $\left(\mathrm{kg} \mathrm{m}^{-1} \mathrm{~s}^{-1}\right)$ & $\rho^{*}$ & density ratio \\
\hline$K$ & interphase exchange coefficient & $\tau$ & stress tensor $(\mathrm{Pa})$ \\
\hline$l$ & turbulence scale (m) & $\varphi$ & angle of internal friction \\
\hline$L$ & characteristic size (m) & $\Phi$ & transferrate of kinetic energy $\left(\mathrm{kg} \mathrm{m}^{-1} \mathrm{~s}^{-3}\right)$ \\
\hline$L_{\mathrm{S}}$ & length $(\mathrm{m})$ & & \\
\hline$P$ & pressure $(\mathrm{Pa})$ & \multicolumn{2}{|c|}{ Subscripts } \\
\hline $\operatorname{Re}$ & Reynolds number & a & main slot \\
\hline$R e_{\mathrm{S}}$ & relative Reynolds number & $\mathrm{b}$ & branch slot \\
\hline $\operatorname{Re}_{D_{\mathrm{H}}}$ & turbulence Reynolds number & col & collision \\
\hline$S$ & modulus of the average strain rate tensor & $\mathrm{fr}$ & friction \\
\hline$S_{i j}$ & strain tensor & $i, \mathrm{j}$ & component \\
\hline$t$ & time $(s)$ & kin & kinetic \\
\hline$U_{s, \|}$ & particle slip velocity parallel to the wall $\left(\mathrm{m} \mathrm{s}^{-1}\right)$ & 1 & liquid phase \\
\hline$v^{0, \pi}$ & velocity $\left(\mathrm{m} \mathrm{s}^{-1}\right)$ & $\mathrm{m}$ & mixture \\
\hline$v_{c}$ & terminal settling velocity of particle swarms $\left(\mathrm{m} \mathrm{s}^{-1}\right)$ & $\max$ & maximum value \\
\hline \multirow[t]{2}{*}{$w$} & width $(\mathrm{m})$ & $\mathrm{s}$ & solid phase \\
\hline & & $\mathrm{t}$ & turbulent flow \\
\hline \multicolumn{2}{|c|}{ Greek letters } & $x, \mathrm{y}, \mathrm{z}$ & axis \\
\hline$\alpha$ & volume fraction & & \\
\hline$\gamma$ & collisional dissipation of energy $\left(\mathrm{kg} \mathrm{m}^{-1} \mathrm{~s}^{-3}\right)$ & & \\
\hline
\end{tabular}

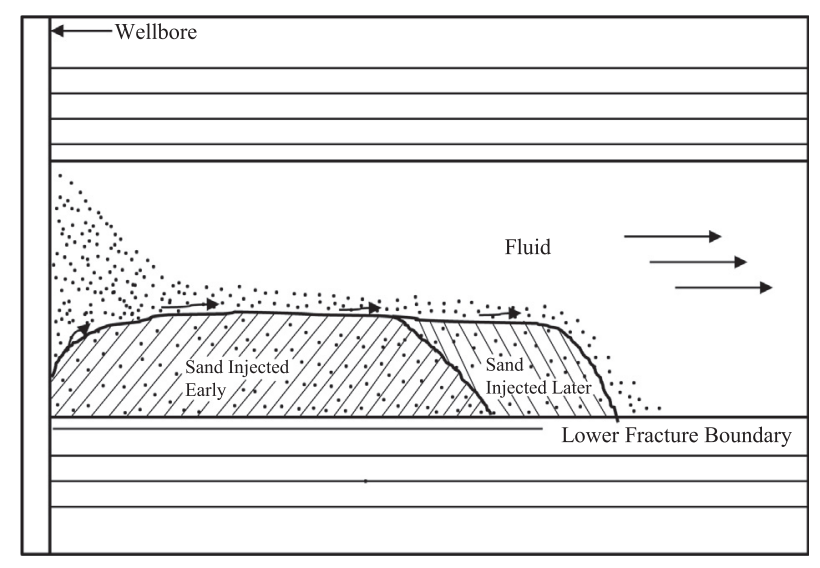

Fig. 1. Sketch of sand transport in planar fracture (Kern et al., 1959).

secondary fractures. For all the configurations, the bypass angle was $90^{\circ}$ and, the width of the slots equaled. The particle size, flow rates and particle volume fraction were considered in experiments to understand the controlling factors of the proppant transport. The proppant either enter into the secondary fracture by the drag force of the fluid or roll into by gravity. Tong and Mohanty (2016) studied the proppant transport in fractures with bypass angle $45^{\circ}, 90^{\circ}$ and $135^{\circ}$, respectively, considering the effects of shear rate and proppant size. Proppant in the secondary fracture increases with the increase of the shear rate and the decrease of bypass angle. However, the effects of the width of the secondary slot and the distance of the intersection from the inlet on the proppant transport and deposition in the cross fractures are not well understood.

The proppant transport and the deposition in the fracture network are very complex and related with complex fracture geometries and network structures (e.g., bypass angle, the width of the fractures), proppant properties (e.g., proppant size and density), fluid properties (e.g., fluid viscosity and density), and boundary conditions (e.g., injection rate, proppant volume fraction). Some studies have been conducted to illustrate the effects of single parameter, but the coupling effect of the controlling factors on proppant-laden flow is not well understood. Dimensional analysis 
is an effective tool to obtain the coupling controlling parameters, catch proper simplification, and result in general conclusions.

To investigate the main controlling parameters in the flow characteristics in the fracture networks, computational fluid dynamics (CFD) method, widely used in the study of two-phase systems such as fluidized bed and pipe slurry, is used in this paper. The problem is simplified as a solid-liquid two-phase flow in cross fractures with different bypass angles and fracture widths at the intersections, without considering the fracture tortuosity, surface roughness, and fluid leakage.

This paper is organized as follows: in Section 2, a numerical model is introduced for describing the solid-liquid two-phase flow in cross fractures by using the CFD method. The dimensionless parameters are derived by dimensional analysis; in Section 3, the presented model is validated by the experimental data of Manoorkar et al. (2016) and Tong and Mohanty (2016), and the effects of the dimensionless controlling parameters on solidliquid two-phase flow in cross fractures are investigated.

\section{Methodology}

\subsection{Problem formulation}

A main slot and two branch slots form four kinds of cross fracture systems (Fig. 2). In the four cases, the size of the main slot is length $\times$ height $\times$ width $=1000 \mathrm{~mm} \times 150 \mathrm{~mm} \times 6 \mathrm{~mm}$, and the width of the branch slot, the bypass angle are varied. The length and the height of the branch slots are the same as that of the main slot, while the width is set as $3 \mathrm{~mm}, 4 \mathrm{~mm}, 5 \mathrm{~mm}$ and $6 \mathrm{~mm}$, respectively. The branch slot closer to the inlet is called the front branch slot, the other is called the rear branch slot. The intersections of two slots are $200 \mathrm{~mm}$ and $600 \mathrm{~mm}$ distant away from the inlet of the main slot. The bypass angle is set as $10^{\circ}, 45^{\circ}, 60^{\circ}$ and $90^{\circ}$, respectively. The flux of solid-liquid two-phase is injected from the left side of the main slot with an constant velocity. The pressures at the right sides of the slots are assumed to equal the atmosphere.

Initially, the cross fractures are filled with the liquid phase without velocity, and the computation domain was free of any particle.

\subsection{Model description}

There are two prevailing kinds of numerical models: EulerianEulerian and Eulerian-Lagrangian for the simulation of two-phase flow (Cornelissen et al., 2007; Kaushal et al., 2012; Shiozawa and McClure, 2016; Zeng et al., 2016). In the Eulerian-Eulerian model (i.e., two-fluid model), the solid and fluid phases are all treated as interpenetrating continua (Askaripour and Dehkordi, 2016). KTGF is introduced to simulate particle collision and friction. The advantage of the Eulerian-Eulerian method is that the calculation is convenient and the disadvantage is that the discrete characteristics of the solid phase can't be described (Zhong et al., 2016). In the Eulerian-Lagrangian model, fluid is described with a Eulerian framework, and each solid particle is resolved in a Lagrangian way (Shiozawa and McClure, 2016; Zeng et al., 2016). The obvious advantage of this method is that each particle can be traced and the disadvantage is that tremendous computational resources is required when the sum of particles is large (Zhong et al., 2016). Considering the two-fluid model is high efficient in computation and can catch the main features of the flow behavior of proppantladen fluid in cross fractures, the Eulerian-Eulerian model is adopted in this paper.

\subsubsection{Continuity equations}

The mass conservation equations of the liquid and solid phases (particles) are expressed as (Jackson, 1997):

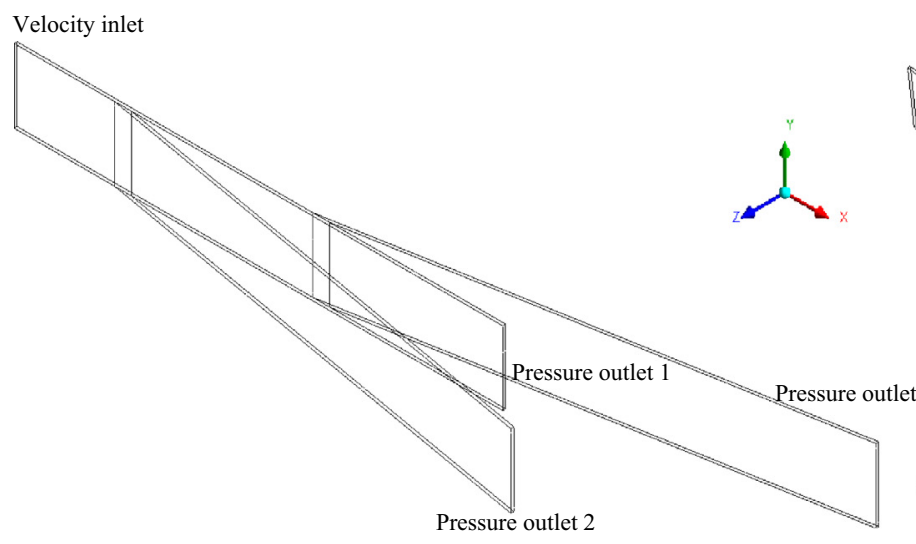

(a) $10^{\circ}$

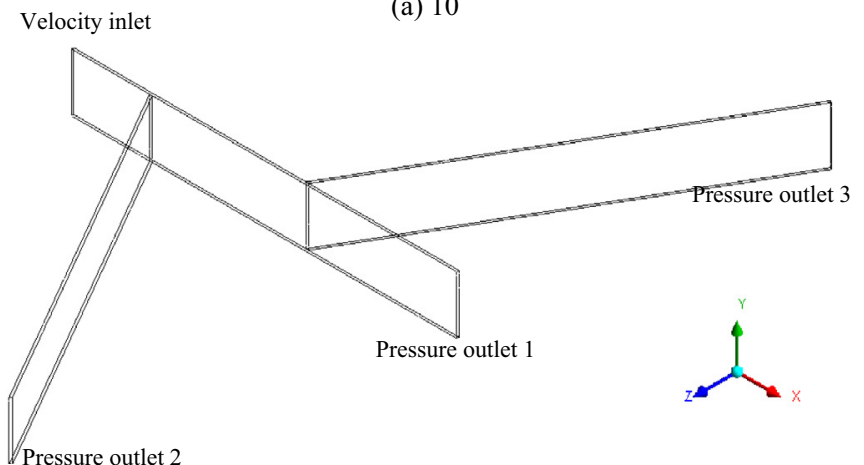

(c) $60^{\circ}$

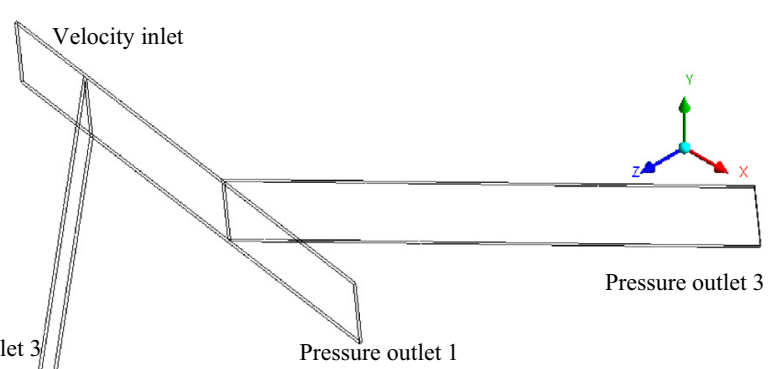

(b) $45^{\circ}$

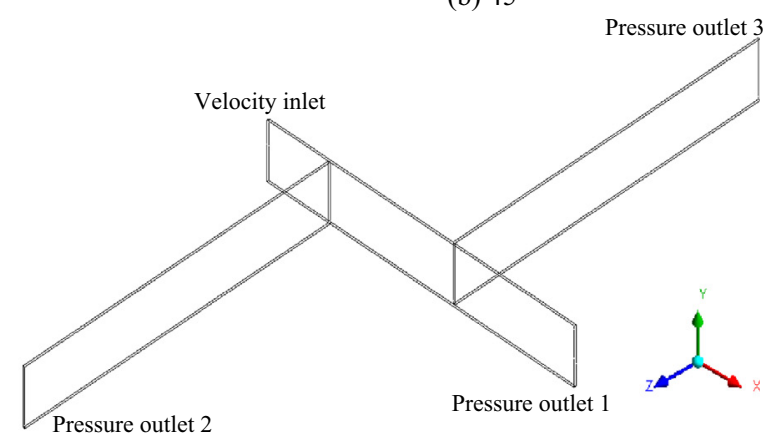

(d) $90^{\circ}$

Fig. 2. Sketch of cross-fracture model. 
$\frac{\partial}{\partial t}\left(\alpha_{1} \rho_{1}\right)+\nabla \cdot\left(\alpha_{1} \rho_{1} \boldsymbol{v}_{1}\right)=0$

$\frac{\partial}{\partial t}\left(\alpha_{\mathrm{s}} \rho_{\mathrm{s}}\right)+\nabla \cdot\left(\alpha_{\mathrm{s}} \rho_{\mathrm{s}} \boldsymbol{v}_{\mathrm{s}}\right)=0$

where $\alpha$ is the volume fraction, dimensionless. $\rho$ is the density, $\mathrm{kg} / \mathrm{m}^{3} . v$ is the velocity, $\mathrm{m} / \mathrm{s}$. The subscripts $1, \mathrm{~s}$ represent the liquid and solid phases, respectively. The volume fractions of the two phases must satisfy:

$\alpha_{1}+\alpha_{s}=1$

The momentum equations for the liquid and particles are written as (Jackson, 1997):

$\frac{\partial}{\partial t}\left(\alpha_{1} \rho_{1} \boldsymbol{v}_{1}\right)+\nabla \cdot\left(\alpha_{1} \rho_{1} \boldsymbol{v}_{1} \boldsymbol{v}_{1}\right)=-\alpha_{1} \nabla P+\nabla \cdot \tau_{1}+\alpha_{1} \rho_{1} g+K_{\mathrm{ls}}\left(\boldsymbol{v}_{1}-\boldsymbol{v}_{\mathrm{s}}\right)$

$\begin{aligned} \frac{\partial}{\partial t}\left(\alpha_{\mathrm{s}} \rho_{\mathrm{s}} \boldsymbol{v}_{\mathrm{s}}\right)+\nabla \cdot\left(\alpha_{\mathrm{s}} \rho_{\mathrm{s}} \boldsymbol{v}_{\mathrm{s}} \boldsymbol{v}_{\mathrm{s}}\right)= & -\alpha_{\mathrm{s}} \nabla P-\nabla P_{\mathrm{s}}+\nabla \cdot \tau_{\mathrm{s}}+\alpha_{\mathrm{s}} \rho_{\mathrm{s}} \mathbf{g} \\ & +K_{\mathrm{sl}}\left(\boldsymbol{v}_{\mathrm{s}}-\boldsymbol{v}_{\mathrm{l}}\right)\end{aligned}$

where $P$ is the liquid phase pressure, $\mathrm{Pa} . P_{\mathrm{s}}$ is the solid phase pressure, Pa. $\tau_{1}$ and $\tau_{s}$ are, respectively, the stress tensors for liquid and solid phases, Pa. $g$ is the gravitational acceleration, $g=9.81 \mathrm{~m} / \mathrm{s}^{2} . K_{\mathrm{sl}}$ represents the interphase momentum exchange coefficient, $K_{\mathrm{sl}}=K_{\mathrm{ls}}, \mathrm{kg} /\left(\mathrm{m}^{3} \cdot \mathrm{s}\right)$.

The constitutive relation for liquid and particles are expressed as:

$\tau_{1}=\alpha_{1} \mu_{1}\left(\nabla \boldsymbol{v}_{1}+\left(\nabla \boldsymbol{v}_{1}\right)^{\mathrm{T}}\right)+\frac{2}{3} \mu_{1} \alpha_{1} \nabla \cdot \boldsymbol{v}_{1} \mathbf{I}$

$\tau_{\mathrm{s}}=\alpha_{\mathrm{s}} \mu_{\mathrm{s}}\left(\nabla \boldsymbol{v}_{\mathrm{s}}+\left(\nabla \boldsymbol{v}_{\mathrm{s}}\right)^{\mathrm{T}}\right)+\alpha_{\mathrm{s}}\left(\lambda_{\mathrm{s}}-\frac{2}{3} \mu_{\mathrm{s}}\right) \nabla \cdot \boldsymbol{v}_{\mathrm{s}} \mathbf{I}$

where $\mu_{1}$ and $\mu_{\mathrm{s}}$ are the shear viscosities, Pa $\cdot \mathrm{s}$. $\lambda_{\mathrm{s}}$ is the bulk viscosity, $\mathrm{Pa} \cdot \mathrm{s}$. I is the unit tensor, dimensionless.

The shear viscosity of solid phase is consisted of three parts: collision viscosity, kinetic viscosity and friction viscosity.

$\mu_{\mathrm{s}}=\mu_{\mathrm{s}, \mathrm{col}}+\mu_{\mathrm{s}, \mathrm{kin}}+\mu_{\mathrm{s}, \mathrm{fr}}$

$\mu_{\mathrm{s}, \mathrm{col}}=\frac{4}{5} \alpha_{\mathrm{s}}^{2} \rho_{\mathrm{s}} d_{\mathrm{s}} g_{0}, \mathrm{ss}\left(1+e_{\mathrm{ss}}\right)\left(\frac{\Theta_{\mathrm{s}}}{\pi}\right)^{\frac{1}{2}}$

$\mu_{\mathrm{s}, \mathrm{kin}}=\frac{\alpha_{\mathrm{s}} \rho_{\mathrm{s}} d_{\mathrm{s}} \sqrt{\Theta_{\mathrm{s}} \pi}}{6\left(3-e_{\mathrm{ss}}\right)}\left[1+\frac{2}{5}\left(1+e_{\mathrm{ss}}\right)\left(3 e_{\mathrm{ss}}-1\right) \alpha_{\mathrm{s}} g_{0}, \mathrm{ss}\right]$

$\mu_{\mathrm{s}, \mathrm{fr}}=\frac{P_{\mathrm{s}} \sin \varphi}{2 \sqrt{\mathrm{I}_{2 D}}}$

$\mathrm{I}_{2 D}=\frac{1}{6}\left[\left(D_{x x}-D_{y y}\right)^{2}+\left(D_{y y}-D_{z z}\right)^{2}+\left(D_{z z}-D_{x x}\right)^{2}\right]+D_{x y}^{2}+D_{y z}^{2}+D_{z x}^{2}$

$D_{i j}=\frac{1}{2}\left(\nabla \boldsymbol{v}_{\mathrm{s}}+\nabla \boldsymbol{v}_{\mathrm{s}}^{\mathrm{T}}\right)$

where $\mu_{\mathrm{s}, \mathrm{col}}$ is the solid collision viscosity, $\mathrm{Pa} \cdot \mathrm{s}$, using the Gidaspow model (Gidaspow, 1994). $\mu_{\mathrm{s}, \mathrm{kin}}$ is the solid kinetic viscosity, Pa $\cdot \mathrm{s}$, using the Syamlal model (Syamlal et al., 1993). $\mu_{\text {s.fr }}$ is the solid friction viscosity, Pa $\cdot s$, using the Schaeffer model (Johnson and Jackson, 1987). $d_{\mathrm{s}}$ represents the particle diameter, $m . e_{\mathrm{ss}}$ represents particleparticle restitution coefficient, taken as $0.9 . g_{0}$, ss is the radial distribution function, dimensionless. $\Theta_{s}$ is the granular temperature, $\mathrm{m}^{2} / \mathrm{s}^{2} . \varphi$ is the angle of internal friction, rad, taken as $\pi / 6 . I_{2 D}$ is the partial stress tensor constant, dimensionless. $D_{i j}$ is the strain tensor for solid phase, $\mathrm{s}^{-1}$.

The bulk viscosity of the solid phase is taken as (Lun et al., 1984):

$\lambda_{\mathrm{s}}=\frac{4}{3} \alpha_{\mathrm{s}}^{2} \rho_{\mathrm{s}} d_{\mathrm{s}} g_{0}, \operatorname{ss}\left(1+e_{\mathrm{ss}}\right)\left(\frac{\Theta_{\mathrm{s}}}{\pi}\right)^{\frac{1}{2}}$

The solid pressure, the momentum exchange of solid particles per unit area per unit time, i.e., the normal stress of the particle, can be evaluated as (Lun et al., 1984):

$P_{\mathrm{s}}=\alpha_{\mathrm{s}} \rho_{\mathrm{s}} \Theta_{\mathrm{s}}+2 \rho_{\mathrm{s}}\left(1+e_{\mathrm{ss}}\right) \alpha_{\mathrm{s}} g_{0}, \mathrm{ss} \Theta_{\mathrm{s}}$

The radial distribution function, a correction factor used to modify the probability of the collision between particles when the particle concentration is high, can be determined by (Ogawa et al.,1980):

$g_{0}\left(\alpha_{\mathrm{s}}\right)=\left[1-\left(\frac{\alpha_{\mathrm{s}}}{\alpha_{\mathrm{s}, \max }}\right)^{\frac{1}{3}}\right]^{-1}$

where $\alpha_{\mathrm{s}}$ is particle volume fraction, dimensionless. $\alpha_{\mathrm{s}, \max }$ is the packing limit and is set 0.63 by default.

The interphase force model proposed by Gidaspow (1994) is used, the interphase momentum exchange coefficient is expressed as:

$K_{\mathrm{ls}}=\left\{\begin{array}{l}\alpha_{1} \geqslant 0.8, \frac{3}{4} C_{D} \frac{\alpha_{\mathrm{s}} \alpha_{1} \rho_{1}\left|\boldsymbol{v}_{\mathrm{s}}-\boldsymbol{v}_{1}\right|}{d_{\mathrm{s}}} \alpha_{1}^{-2.65} \\ \alpha_{1}<0.8,150 \frac{\alpha_{\mathrm{s}}\left(1-\alpha_{1}\right) \mu_{1}}{\alpha_{1} d_{\mathrm{s}}^{2}}+1.75 \frac{\rho_{1} \alpha_{\mathrm{s}}\left|\boldsymbol{v}_{\mathrm{s}}-\boldsymbol{v}_{1}\right|}{d_{\mathrm{s}}}\end{array}\right.$

$C_{D}=\frac{24}{\alpha_{1} \operatorname{Re}_{s}}\left[1+0.15\left(\alpha_{1} \operatorname{Re}_{s}\right)^{0.687}\right]$

$\operatorname{Re}_{\mathrm{s}}=\frac{\rho_{\mathrm{l}} d_{\mathrm{s}}\left|\boldsymbol{v}_{\mathrm{s}}-\boldsymbol{v}_{1}\right|}{\mu_{1}}$

where $C_{D}$ is the drag coefficient, dimensionless. $R e_{\mathrm{s}}$ is the relative Reynolds number, dimensionless.

\subsubsection{Granular temperature equation}

The granular temperature of the solid phase is proportional to the kinetic energy of the random motion of the particles. The transport equation from the kinetic energy theory is expressed as (Ding and Gidaspow, 1990):

$\frac{3}{2}\left[\frac{\partial}{\partial t}\left(\rho_{\mathrm{s}} \alpha_{\mathrm{s}} \Theta_{\mathrm{s}}\right)+\nabla \cdot\left(\rho_{\mathrm{s}} \alpha_{\mathrm{s}} \boldsymbol{v}_{\mathrm{s}} \Theta_{\mathrm{s}}\right)\right]=\left(-P_{\mathrm{s}} \mathbf{I}+\boldsymbol{\tau}_{\mathrm{s}}\right)$

$: \nabla \boldsymbol{v}_{\mathrm{s}}+\nabla \cdot\left(k_{\Theta \mathrm{s}} \nabla \Theta_{\mathrm{s}}\right)-\gamma_{\Theta \mathrm{s}}+\Phi_{\mathrm{ls}}$

where $\gamma_{\Theta s}$ is the collisional dissipation of energy, $\mathrm{kg} /\left(\mathrm{m} \cdot \mathrm{s}^{3}\right)$, can be evaluated by Lun et al. (1984):

$\gamma_{\Theta s}=\frac{12\left(1-e_{\mathrm{ss}}^{2}\right) g_{0}, \mathrm{ss}}{d_{\mathrm{s}} \sqrt{\pi}} \rho_{\mathrm{s}} \alpha_{\mathrm{s}}^{2} \Theta_{\mathrm{s}}^{3 / 2}$

$\Phi_{\mathrm{ls}}$ is the energy exchange between solid and fluid phases, $\mathrm{kg} /\left(\mathrm{m} \cdot \mathrm{s}^{3}\right)$, and can be expressed as (Gidaspow et al., 1992):

$\Phi_{\mathrm{ls}}=-3 K_{\mathrm{ls}} \Theta_{\mathrm{s}}$

$k_{\Theta \mathrm{s}}$ is the diffusion coefficient, $\mathrm{kg} /(\mathrm{m} \cdot \mathrm{s})$, and can be described by (Gidaspow et al., 1992):

$$
\begin{aligned}
k_{\Theta} \mathrm{S}= & \frac{25 \rho_{\mathrm{s}} d_{\mathrm{s}} \sqrt{\Theta_{\mathrm{s}} \pi}}{64\left(1+e_{\mathrm{ss}}\right) g_{0}, \mathrm{ss}}\left[1+\frac{6}{5} \alpha_{\mathrm{s}} g_{0}, \mathrm{ss}\left(1+e_{\mathrm{ss}}\right)\right]^{2} \\
& +2 \rho_{\mathrm{s}} \alpha_{\mathrm{s}}^{2} d_{\mathrm{s}}\left(1+e_{\mathrm{ss}}\right) g_{0}, \mathrm{ss} \sqrt{\frac{\Theta_{\mathrm{s}}}{\pi}}
\end{aligned}
$$




\subsubsection{Turbulence equations}

The renormalization group (RNG) $k-\varepsilon$ turbulence model is adopted to describe the turbulent motion of the liquid phase. The turbulent kinetic energy and dissipation rate equations are (Orszag et al., 1993):

$\frac{\partial}{\partial t}\left(\rho_{\mathrm{m}} k\right)+\nabla \cdot\left(\rho_{\mathrm{m}} \boldsymbol{v}_{\mathrm{m}} k\right)=\nabla \cdot\left(\alpha_{k} \mu_{\mathrm{t}} \nabla k\right)+G_{k, \mathrm{~m}}-\rho_{\mathrm{m}} \varepsilon$

$\frac{\partial}{\partial t}\left(\rho_{\mathrm{m}} \varepsilon\right)+\nabla \cdot\left(\rho_{\mathrm{m}} \boldsymbol{v}_{\mathrm{m}} \varepsilon\right)=\nabla \cdot\left(\alpha_{\varepsilon} \mu_{\mathrm{t}} \nabla \varepsilon\right)+\frac{\varepsilon}{k}\left(C_{1 \varepsilon} G_{k, \mathrm{~m}}-C_{2 \varepsilon} \rho_{\mathrm{m}} \varepsilon\right)-R_{\varepsilon}$

where $k$ is the turbulence kinetic energy, $\mathrm{m}^{2} / \mathrm{s}^{2} . \varepsilon$ is the dissipation rate, $\mathrm{m}^{2} / \mathrm{s}^{3} . \alpha_{k}$ and $\alpha_{\varepsilon}$ are respectively the inverse effective Prandtl numbers for $k$ and $\varepsilon$, dimensionless, taken as 1.393. $\rho_{\mathrm{m}}$ is the density of the mixture, $\mathrm{kg} / \mathrm{m}^{3}, \rho_{\mathrm{m}}=\alpha_{\mathrm{l}} \rho_{\mathrm{l}}+\alpha_{\mathrm{s}} \rho_{\mathrm{s}} . \boldsymbol{v}_{\mathrm{m}}$ is the velocity of the mixture, $\mathrm{m} / \mathrm{s}, \boldsymbol{v}_{\mathrm{m}}=\left(\alpha_{\mathrm{l}} \rho_{\mathrm{l}} \boldsymbol{v}_{\mathrm{l}}+\alpha_{\mathrm{s}} \rho_{\mathrm{s}} \boldsymbol{v}_{\mathrm{s}}\right) / \rho_{\mathrm{m}} . G_{k, \mathrm{~m}}$ is the generation of turbulent kinetic energy due to the average velocity gradient, $\mathrm{kg} /\left(\mathrm{m} \cdot \mathrm{s}^{3}\right), G_{k, \mathrm{~m}}=\mu_{\mathrm{t}}\left(\nabla \boldsymbol{v}_{\mathrm{m}}+\left(\nabla \boldsymbol{v}_{\mathrm{m}}\right)^{\mathrm{T}}\right): \nabla \boldsymbol{v}_{\mathrm{m}} \cdot \mu_{\mathrm{t}}$ is the turbulent viscosity, Pa $\cdot \mathrm{s}, \mu_{\mathrm{t}}=\rho_{\mathrm{m}} C_{\mu} k^{2} / \varepsilon, C_{\mu}=0.0845$. Compared to standard $k-\varepsilon$ model, the RNG $k-\varepsilon$ model has one more term $R_{\varepsilon}$ in the $\varepsilon$ equation, $R_{\varepsilon}$ is defined as $R_{\varepsilon}=C_{\mu} \rho_{\mathrm{m}} \eta^{3}\left(1-\eta / \eta_{0}\right) \varepsilon^{2} /\left(1+\beta \eta^{3}\right) k$, $\eta_{0}=4.38, \beta=0.012$. $S$ is the modulus of the average strain rate tensor, $S \equiv \sqrt{2 S_{i j} S_{i j}}, S_{i j}=\left(\partial u_{j} / \partial x_{i}+\partial u_{i} / \partial x_{j}\right) / 2 . C_{1 \varepsilon}$ and $C_{2 \varepsilon}$ are the model constants, dimensionless, taken as $C_{1 \varepsilon}=1.42, C_{2 \varepsilon}=1.68$.

\subsubsection{Boundary conditions and numerical scheme}

The RNG $k-\varepsilon$ model was adopted to describe the inlet turbulence, the following empirical formula was used to calculate the turbulence intensity and turbulence scale:

$I=0.16\left(\operatorname{Re}_{D_{\mathrm{H}}}\right)^{-\frac{1}{8}}$

$l=0.07 L$

where $R e_{D_{\mathrm{H}}}$ is turbulence Reynolds number, dimensionless, $R e_{D_{H}}=\rho_{1} v_{0} D_{\mathrm{H}} / \mu_{\mathrm{l}} . v_{0}$ is injection velocity of the mixture of particles and water. $D_{\mathrm{H}}$ is hydraulic diameter, taken as width of the main slot. $L$ is characteristic size, taken as height of the main slot. The inlet granular temperature was taken as $10^{-5} \mathrm{~m}^{2} / \mathrm{s}^{2}$. Inner walls of the slot were set as no slip wall boundary condition for the liquid. The Johnson and Jackson boundary condition was used for the solid phase.

$\tau_{\mathrm{s}}=-\frac{\pi}{6} \sqrt{3} \xi \frac{\alpha_{\mathrm{s}}}{\alpha_{\mathrm{s}, \max }} \rho_{\mathrm{s}} g_{0}, \mathrm{ss} \sqrt{\Theta_{\mathrm{s}}} \boldsymbol{U}_{\mathrm{s}, \|}$

where $\boldsymbol{U}_{\mathrm{s}, \|}$ is the particle slip velocity parallel to the wall, $\mathrm{m} / \mathrm{s}$. $\xi$ is the specularity coefficient between the particle and the wall, dimensionless, taken as 0.01 .
The phase coupled SIMPLE method was used for pressurevelocity coupling, and gradient was discretized with the GreenGauss cell-based method. A first order upwind discretization was used for the equation of volume fraction, and a second order upwind discretization was used for the momentum equation, turbulent kinetic and turbulent dissipation energy equations. The convergence criterion was that the residual value of each calculated variable was less than $10^{-3}$. The values of under-relaxation factors of the density, momentum, volume fraction, turbulence kinetic energy and turbulence energy dissipation were set as 0.5 . The time step was set as $10^{-3} \mathrm{~s}$, and the max iterations in one time step were set as 50 .

Fig. 3 shows the mesh used for this numerical simulation, and a hexahedral structured grid was adopted to guarantee the computation accuracy and convergence. To study the sensitivity of the simulation results to grid sizes, three kinds of grid sizes in length $\times$ height $\times$ width direction as $4 \mathrm{~mm} \times 4 \mathrm{~mm} \times 1 \mathrm{~mm}, 2 \mathrm{~mm} \times 2$ $\mathrm{mm} \times 1.5 \mathrm{~mm}$ and $2 \mathrm{~mm} \times 2.5 \mathrm{~mm} \times 1 \mathrm{~mm}$ were examined, respectively. The numbers of mesh elements at the above resolutions for geometries with different branch slot widths are shown in Table 1. Fig. 4 shows the variations of particles volume fraction with time in cross fractures with different branch slot widths for different mesh resolutions. It can be seen in Fig. 4a, there is a significant difference in the volume fraction of particles for the grid sizes of $4 \mathrm{~mm} \times 4 \mathrm{~mm} \times 1 \mathrm{~mm}$ and $2 \mathrm{~mm} \times 2 \mathrm{~mm} \times 1.5 \mathrm{~mm}$, and this discrepancy is reduced for the grid sizes of $2 \mathrm{~mm} \times 2 \mathrm{~mm} \times 1.5$ $\mathrm{mm}$ and $2 \mathrm{~mm} \times 2.5 \mathrm{~mm} \times 1 \mathrm{~mm}$. The grid size of $2 \mathrm{~mm} \times 2 \mathrm{~mm}$ $\times 1.5 \mathrm{~mm}$ should be sufficiently fine so that incremental refinement would slightly affect the volume fraction of particles in slots. The trend is similar in Fig. $4 \mathrm{~b}-\mathrm{d}$. Therefore, the grid size of $2 \mathrm{~mm} \times$ $2 \mathrm{~mm} \times 1.5 \mathrm{~mm}$ was chosen in the following simulations consider-

Table 1

Numbers of mesh elements at different resolutions.

\begin{tabular}{lll}
\hline $\begin{array}{l}\text { Width of } \\
\text { branch slots }\end{array}$ & Mesh resolutions & $\begin{array}{l}\text { Number of mesh } \\
\text { elements }\end{array}$ \\
\hline $\mathrm{w}_{\mathrm{b}}=3 \mathrm{~mm}$ & Coarse grid $(4 \times 4 \times 1 \mathrm{~mm})$ & 132,696 \\
& Medium grid $(2 \times 2 \times 1.5 \mathrm{~mm})$ & 373,650 \\
& Fine grid $(2 \times 2.5 \times 1 \mathrm{~mm})$ & 418,560 \\
$\mathrm{w}_{\mathrm{b}}=4 \mathrm{~mm}$ & Coarse grid $(4 \times 4 \times 1 \mathrm{~mm})$ & 170,088 \\
& Medium grid $(2 \times 2 \times 1.5 \mathrm{~mm})$ & 448,800 \\
& Fine grid $(2 \times 2.5 \times 1 \mathrm{~mm})$ & 537,120 \\
$\mathrm{w}_{\mathrm{b}}=5 \mathrm{~mm}$ & Coarse grid $(4 \times 4 \times 1 \mathrm{~mm})$ & 189,468 \\
& Medium grid $(2 \times 2 \times 1.5 \mathrm{~mm})$ & 522,000 \\
& Fine grid $(2 \times 2.5 \times 1 \mathrm{~mm})$ & 598,320 \\
$\mathrm{w}_{\mathrm{b}}=6 \mathrm{~mm}$ & Coarse grid $(4 \times 4 \times 1 \mathrm{~mm})$ & 207,784 \\
& Medium grid $(2 \times 2 \times 1.5 \mathrm{~mm})$ & 596,400 \\
& Fine grid $(2 \times 2.5 \times 1 \mathrm{~mm})$ & 656,160 \\
\hline
\end{tabular}

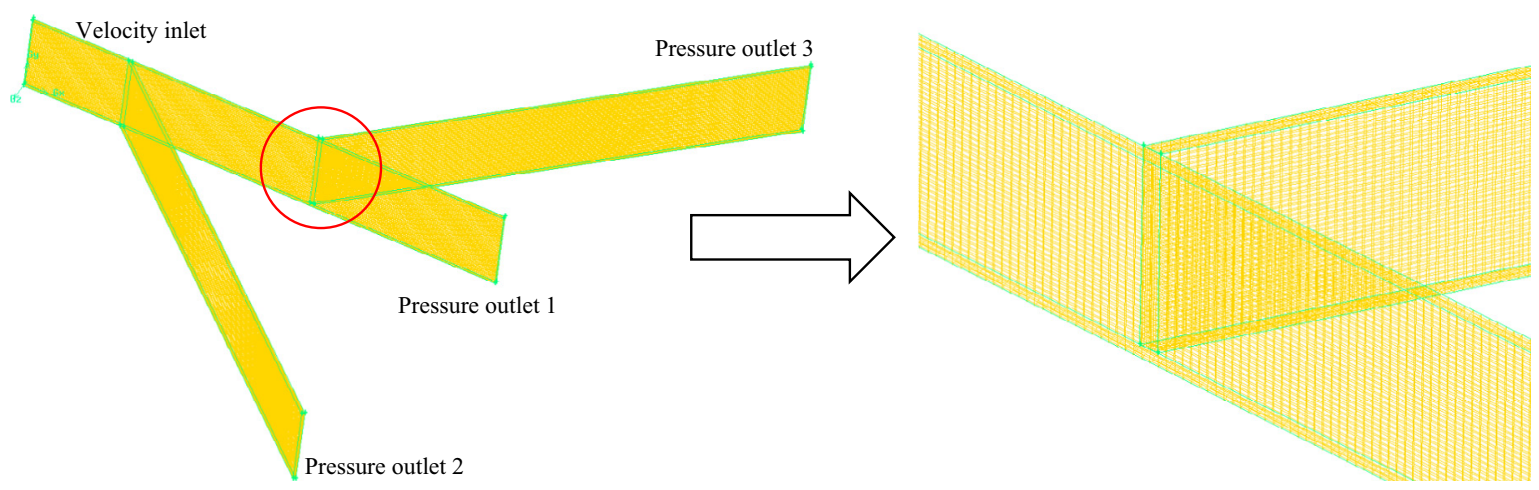

Fig. 3. Structured mesh of the cross fractures. 




(a) $\mathrm{w}_{\mathrm{b}}=3 \mathrm{~mm}$

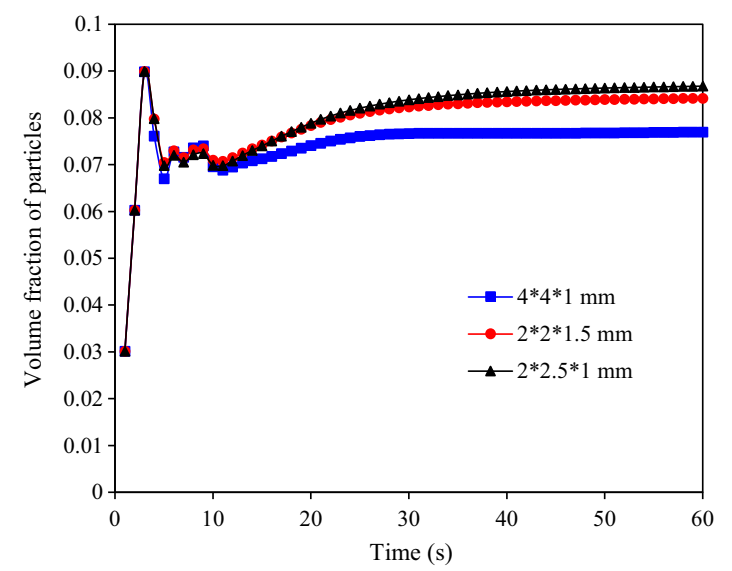

(c) $\mathrm{w}_{\mathrm{b}}=5 \mathrm{~mm}$



(b) $\mathrm{w}_{\mathrm{b}}=4 \mathrm{~mm}$

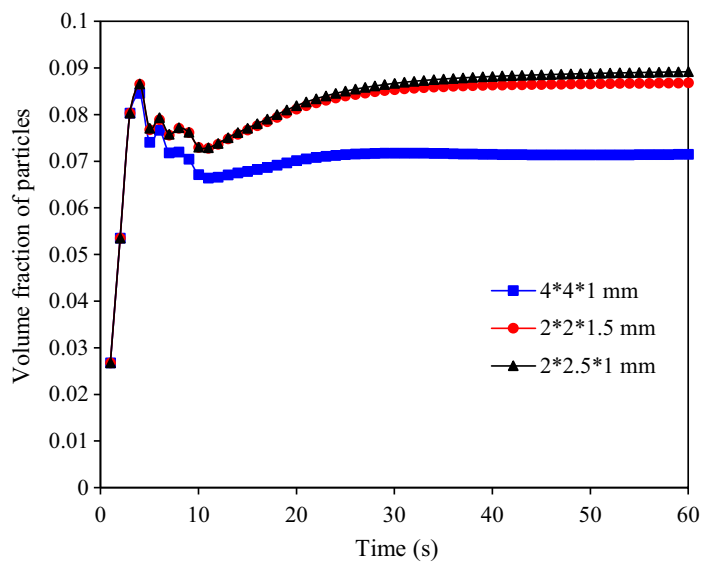

(d) $\mathrm{w}_{\mathrm{b}}=6 \mathrm{~mm}$

Fig. 4. Comparisons of the particles volume fraction with time for different mesh resolutions. The width of the branch slots $w_{\mathrm{b}}$ is (a) $3 \mathrm{~mm}$, (b) $4 \mathrm{~mm}$, (c) $5 \mathrm{~mm}$ and (d) $6 \mathrm{~mm}$, respectively. $\theta=45^{\circ}, \alpha_{\mathrm{s} 0}=8 \%, d_{\mathrm{s}} / w_{\mathrm{b}}=0.083, A r=127.4, \operatorname{Re}=100$.

ing the influence of computation time and calculation accuracy. A wall function consists of a series of semi-empirical formulas, which can calculate the flow field near-wall cells by substituting the fine grids. The standard wall function proposed by Lanuder and Spalding (1974) was used and the value of $\mathrm{y}^{+}$was ranged from 30 to 75 in the present study.

\subsection{Dimensional analysis}

Dimensional analysis (Tan, 2011) was applied to derive the dimensionless parameters describing the process. According to Eqs. (1)-(23) and boundary conditions, the factors affecting the solid-liquid two-phase flow in cross fractures are listed as follows:

Cross fractures' geometrical parameters: bypass angle $\theta$, the width of the main slot $w_{\mathrm{a}}$, the width of branch slots $w_{\mathrm{b}}$, the height of the slot $H$, the length of the main and the branch slot $L_{\mathrm{s}}$.

Particle properties: density $\rho_{\mathrm{s}}$, diameter $d_{\mathrm{s}}$ (assumed as spherical shape).

Liquid properties: density $\rho_{1}$, viscosity $\mu_{1}$.

Boundary conditions: injection velocity $v_{0}$, inlet particle volume fraction $\alpha_{s 0}$, gravity acceleration $g$. The distribution of the concentration, velocity and pressure at any position can be expressed in the following function:

$\left(\alpha_{i}, v_{i}, P\right)=f\left(\theta, w_{\mathrm{a}}, w_{\mathrm{b}}, H, L_{\mathrm{s}} ; \rho_{\mathrm{s}}, d_{\mathrm{s}} ; \rho_{1}, \mu_{1} ; v_{0}, \alpha_{\mathrm{s} 0}, g\right)$

Eq. (29) can be nondimensionlized by using the particle diameter $d_{s}$, injection velocity $v_{0}$ and liquid density $\rho_{1}$ : $\left(\alpha_{i}, \frac{v_{i}}{v_{0}}, \frac{P}{\rho_{1} v_{0}^{2}}\right)=f\left(\theta, \frac{d_{\mathrm{s}}}{w_{\mathrm{a}}}, \frac{d_{\mathrm{s}}}{w_{\mathrm{b}}}, \frac{d_{\mathrm{s}}}{H}, \frac{d_{\mathrm{s}}}{L_{\mathrm{s}}}, \frac{\rho_{\mathrm{s}}}{\rho_{\mathrm{l}}}, \frac{\rho_{\mathrm{l}} v_{0} d_{\mathrm{s}}}{\mu_{\mathrm{l}}}, \alpha_{\mathrm{s} 0}, \frac{v_{0}^{2}}{g d_{\mathrm{s}}}\right)$

where $\rho_{1} v_{0} d_{\mathrm{s}} / \mu_{1}$ is Reynolds number Re that represents the ratio of inertia effect to viscosity effect. $v_{0}^{2} / g d_{s}$ is Froude number $F r$ that represents the ratio of inertia effect to gravity effect. $\rho_{\mathrm{s}} / \rho_{\mathrm{l}}$ is the density ratio $\rho^{*} . d_{\mathrm{s}} / w_{\mathrm{a}}$ and $d_{\mathrm{s}} / w_{\mathrm{b}}$ is the ratio of particle size to slot width. $d_{\mathrm{s}} / H$ is the ratio of particle size to slot height. $d_{\mathrm{s}} / L_{\mathrm{s}}$ is the ratio of particle size to slot length.

Archimedes number $\mathrm{Ar}$ is thought more suited for describing the particle settlement which can be expressed as (Kuwagi et al., 2014):

$A r=\frac{\left(\rho_{\mathrm{s}}-\rho_{\mathrm{l}}\right) \rho_{\mathrm{l}} d_{\mathrm{s}}^{3} g}{\mu_{\mathrm{l}}^{2}}=\frac{\left(\rho^{*}-1\right) R e^{2}}{\mathrm{Fr}}$

Then Eq. (30) can be rewritten as:

$\left(\alpha_{i}, \frac{v_{i}}{v_{0}}, \frac{P}{\rho_{\mathrm{l}} v_{0}^{2}}\right)=f\left(\theta, \frac{d_{\mathrm{s}}}{w_{\mathrm{a}}}, \frac{d_{\mathrm{s}}}{w_{\mathrm{b}}}, \frac{d_{\mathrm{s}}}{H}, \frac{d_{\mathrm{s}}}{L_{\mathrm{s}}}, \rho^{*}, \operatorname{Re}, \alpha_{\mathrm{s} 0}, A r\right)$

The size effects of the flow on particle motion was not considered, hence $d_{s} / w_{\mathrm{a}}, d_{\mathrm{s}} / H$ and $d_{\mathrm{s}} / L_{\mathrm{s}}$ were set to be constant. The density ratio of particle-to-liquid was also constant. Therefore, the Eq. (32) can be simplified as:

$\left(\alpha_{i}, \frac{v_{i}}{v_{0}}, \frac{P}{\rho_{l} v_{0}^{2}}\right)=f\left(\theta, \alpha_{\mathrm{s} 0}, \frac{d_{\mathrm{s}}}{w_{\mathrm{b}}}, A r, \operatorname{Re}\right)$ 
Table 2

Parameters in the simulation.

\begin{tabular}{|c|c|c|c|c|c|c|c|c|c|c|c|}
\hline \multirow{2}{*}{$\begin{array}{l}\text { Case } \\
\#\end{array}$} & \multirow{2}{*}{$\begin{array}{l}\text { Branch slots } \\
\text { Width } \\
W_{b}(\mathrm{~mm})\end{array}$} & \multicolumn{2}{|c|}{ Particle phase } & \multicolumn{2}{|c|}{ Liquid phase } & \multirow{2}{*}{$\begin{array}{l}\text { Injection rate } \\
v_{0}(\mathrm{~m} / \mathrm{s})\end{array}$} & \multicolumn{5}{|c|}{ Dimensionless numbers } \\
\hline & & $\begin{array}{l}\rho_{s}\left(\mathrm{~kg} / \mathrm{m}^{3}\right) \\
\text { Density }\end{array}$ & $\begin{array}{l}\text { Diameter } \\
d_{s}(\mathrm{~mm})\end{array}$ & $\begin{array}{l}\text { Density } \\
\rho\left(\mathrm{kg} / \mathrm{m}^{3}\right)\end{array}$ & $\begin{array}{l}\text { Viscosity } \\
\mu_{1}(\mathrm{~Pa} \cdot \mathrm{s})\end{array}$ & & $\theta$ & $\alpha_{\mathrm{s} 0}$ & $d_{s} / w_{b}$ & $A r$ & $\operatorname{Re}$ \\
\hline 1 & 6 & 3600 & 0.5 & 1000 & $5.0 \times 10^{-3}$ & 1 & $10^{\circ}$ & $8 \%$ & 0.083 & 127.4 & 100 \\
\hline 2 & 6 & 3600 & 0.5 & 1000 & $5.0 \times 10^{-3}$ & 1 & $45^{\circ}$ & $8 \%$ & 0.083 & 127.4 & 100 \\
\hline 3 & 6 & 3600 & 0.5 & 1000 & $5.0 \times 10^{-3}$ & 1 & $60^{\circ}$ & $8 \%$ & 0.083 & 127.4 & 100 \\
\hline 4 & 6 & 3600 & 0.5 & 1000 & $5.0 \times 10^{-3}$ & 1 & $90^{\circ}$ & $8 \%$ & 0.083 & 127.4 & 100 \\
\hline 5 & 3 & 3600 & 0.5 & 1000 & $5.0 \times 10^{-3}$ & 1 & $45^{\circ}$ & $8 \%$ & 0.167 & 127.4 & 100 \\
\hline 6 & 4 & 3600 & 0.5 & 1000 & $5.0 \times 10^{-3}$ & 1 & $45^{\circ}$ & $8 \%$ & 0.125 & 127.4 & 100 \\
\hline 7 & 5 & 3600 & 0.5 & 1000 & $5.0 \times 10^{-3}$ & 1 & $45^{\circ}$ & $8 \%$ & 0.1 & 127.4 & 100 \\
\hline 8 & 6 & 3600 & 0.5 & 1000 & $5.0 \times 10^{-3}$ & 1 & $90^{\circ}$ & $2.70 \%$ & 0.083 & 127.4 & 100 \\
\hline 9 & 6 & 3600 & 0.5 & 1000 & $5.0 \times 10^{-3}$ & 1 & $90^{\circ}$ & $13 \%$ & 0.083 & 127.4 & 100 \\
\hline 10 & 6 & 3600 & 0.5 & 1000 & $5.0 \times 10^{-3}$ & 1 & $90^{\circ}$ & $18 \%$ & 0.083 & 127.4 & 100 \\
\hline 11 & 6 & 3600 & 0.5 & 1000 & $5.0 \times 10^{-3}$ & 1.5 & $90^{\circ}$ & $8 \%$ & 0.083 & 127.4 & 150 \\
\hline 12 & 6 & 3600 & 0.5 & 1000 & $5.0 \times 10^{-3}$ & 2 & $90^{\circ}$ & $8 \%$ & 0.083 & 127.4 & 200 \\
\hline 13 & 6 & 3600 & 0.5 & 1000 & $5.0 \times 10^{-3}$ & 3 & $90^{\circ}$ & $8 \%$ & 0.083 & 127.4 & 300 \\
\hline 14 & 6 & 3200 & 0.5 & 888.9 & $5.0 \times 10^{-3}$ & 1.125 & $90^{\circ}$ & $8 \%$ & 0.083 & 100.7 & 100 \\
\hline 15 & 6 & 2800 & 0.5 & 777.8 & $5.0 \times 10^{-3}$ & 1.286 & $90^{\circ}$ & $8 \%$ & 0.083 & 77.1 & 100 \\
\hline 16 & 6 & 2400 & 0.5 & 666.7 & $5.0 \times 10^{-3}$ & 1.5 & $90^{\circ}$ & $8 \%$ & 0.083 & 56.6 & 100 \\
\hline
\end{tabular}

The effects of the dimensionless parameters in Eq. (33) on the particle transport and flow characteristics were investigated. The liquid phase was selected as a Newtonian fluid with varied in densities and viscosities for simplification. The particles were assumed to be spheres with the same diameters. 16 cases were considered and listed with parameters in Table 2 in the numerical simulations.

\section{Results and discussion}

In this section, the model is firstly validated by the experimental data of Manoorkar et al. (2016) and Tong and Mohanty (2016), then the effects of six dimensional numbers, i.e., the bypass angle, inlet particle volume fraction, the ratio of particle size to branch slot width, the Archimedes number and the Reynolds number, are investigated. The concentration distribution and flow field of solid particles in both main and branch slots, the particle transport in intersections, are investigated.

\subsection{Model validation}

The simulation results by the above presented model are firstly compared with the experimental results of Manoorkar et al. (2016). The particle-laden flow in T-bifurcations for a range of Reynolds numbers was studied by Manoorkar et al. (2016). The T geometry is shown in Fig. 5. The particle-laden fluid flows into the Tbifurcations from the left inlet, and the outlet from both branches are open to atmosphere. The parameters in the experiment are listed in Table 3, and used for the numerical verification.

The predicted distribution of particles at the intersection of the numerical simulation is firstly compared with the experimental data (Fig. 6). Both results are similar that the particles transport along the center of the square cross section and accumulate at the intersection. The computed $\beta_{\text {particle }}$ (the ratio of the mass of the particles in the straight branch to the total) changing with the Reynolds number is then compared with the experimental results. The two results is with an error less than $0-5 \%$ (Fig. 7). The error is caused by the difference of surface roughness in numerical simulation and experiments.

The second comparison between simulation results and experiment data by Tong and Mohanty (2016) was conducted to verify the accuracy of the presented model. The distribution of sand bed in a transparent fracture slots with bypass angle $45^{\circ}, 90^{\circ}$ and $135^{\circ}$ was investigated by a series of experiments. Detail descriptions of the experiments can be found in the literature. The geometry of the main slot and bypass slot are shown in Fig. 8. The entrance is simplified as a rectangular opening and the outlet is

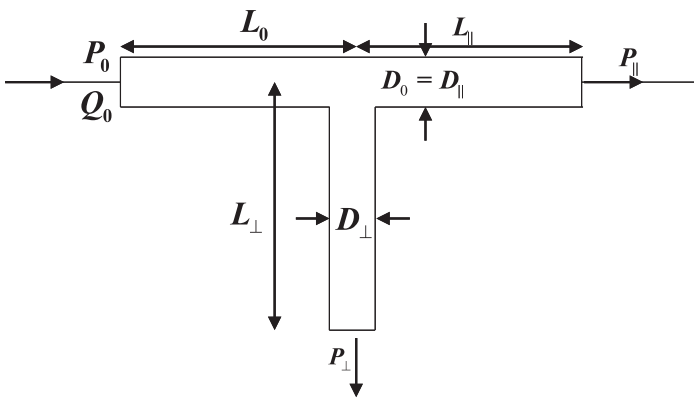

Fig. 5. Schematic of the experimental setup (Manoorkar et al., 2016). $L_{\|}=L_{\perp}=L_{0}=140 \mathrm{~mm}, D_{\|}=D_{\perp}=D_{0}=24 \mathrm{~mm}, P_{\|}=P_{\perp}=$ atmospheric pressure.

Table 3

Parameters in the experiment (Manoorkar et al., 2016).

\begin{tabular}{|c|c|c|c|c|c|c|c|}
\hline Particle density $\rho_{s}\left(\mathrm{~kg} / \mathrm{m}^{3}\right)$ & Particle diameter $d_{s}(\mathrm{~mm})$ & Liquid density $\rho\left(\mathrm{kg} / \mathrm{m}^{3}\right)$ & Liquid viscosity $\mu_{1}(\mathrm{~Pa} \cdot \mathrm{s})$ & $\alpha_{\mathrm{s} 0}$ & $d_{s} / w_{b}$ & $A r$ & $R e$ \\
\hline 1050 & 0.24 & 1024 & 0.0023 & 0.12 & 0.1 & 681.8 & $50,100,200,300$ \\
\hline
\end{tabular}




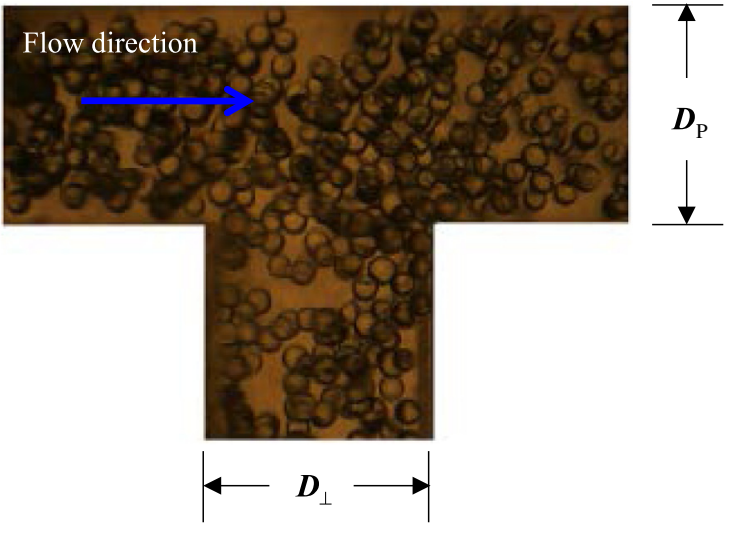

(a)

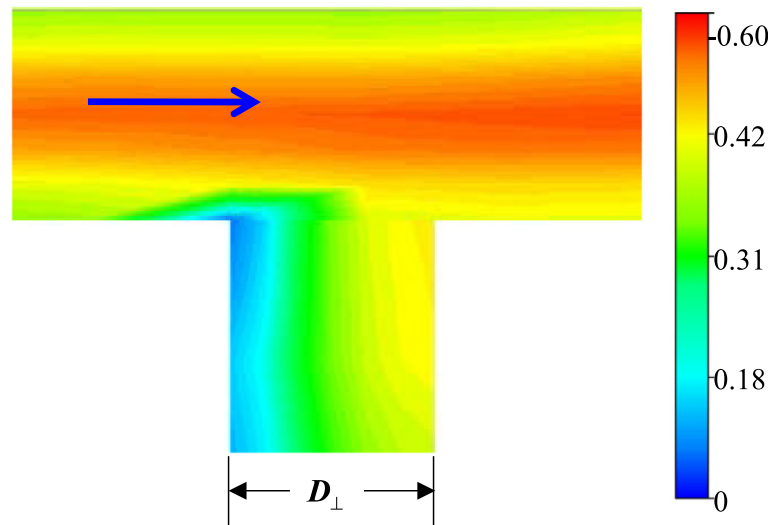

(b)

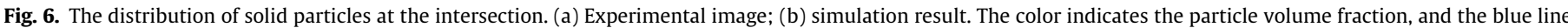

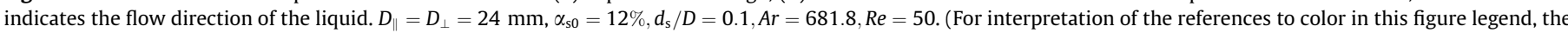
reader is referred to the web version of this article.)

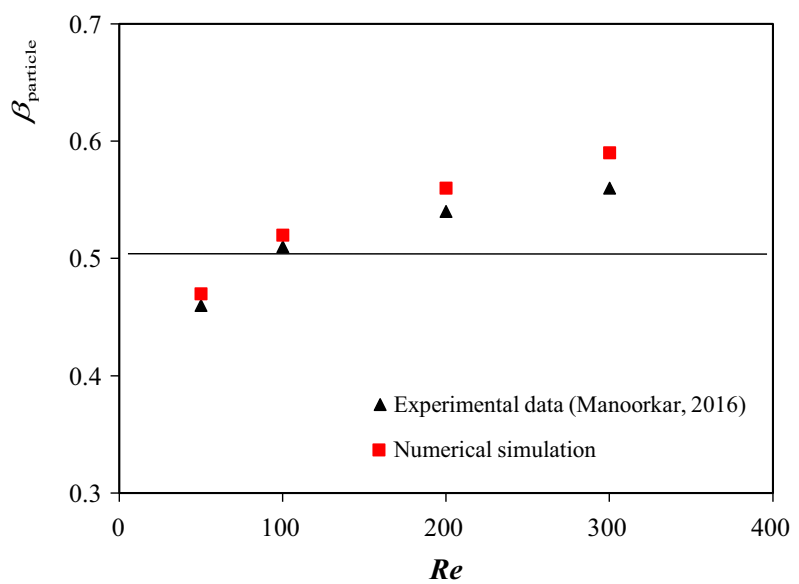

Fig. 7. Comparisons between the experimental data and the simulation results for $\beta_{\text {particle }}$ at $\alpha_{\mathrm{s} 0}=12 \%, d_{\mathrm{s}} / D=0.1, A r=681.8$.

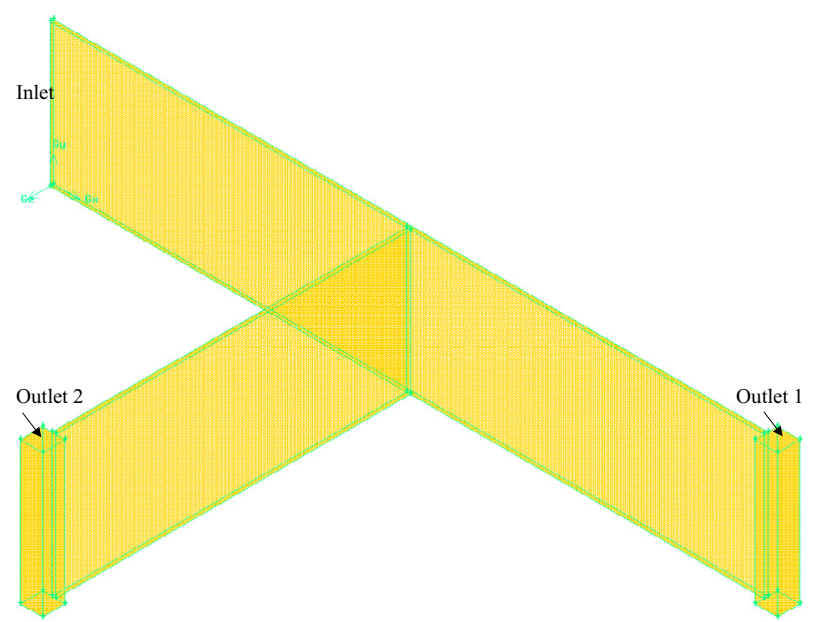

Fig. 8. Computation geometry and mesh (Tong and Mohanty, 2016). 
Table 4

Parameters used in the present simulation (Tong and Mohanty, 2016).

\begin{tabular}{lll}
\hline Parameters & Units & Value \\
\hline Length, height and width of the main slot & $\mathrm{mm}$ & $380,76,2$ \\
Length, height and width of the bypass slot & $\mathrm{mm}$ & $190,76,2$ \\
Length of the outlet well & $\mathrm{mm}$ & 12 \\
Grid size & $\mathrm{mm}$ & $1 \times 1 \times 1$ \\
Bypass angle & $\mathrm{rad}$ & $\pi / 2$ \\
Particle density & $\mathrm{kg} / \mathrm{m}^{3}$ & 2650 \\
Particle diameter & $\mathrm{mm}$ & $0.6,0.7$ \\
Liquid density & $\mathrm{kg} / \mathrm{m}^{3}$ & 998.2 \\
Liquid viscosity & $\mathrm{Pa} \cdot \mathrm{s}$ & 0.001 \\
Injection velocity & $\mathrm{m} / \mathrm{s}$ & 0.2 \\
Inlet particle volume fraction & Dimensionless & 0.019 \\
Ratio of particle diameter to branch slot width & Dimensionless & $0.3,0.35$ \\
Archimedes number $A r$ & Dimensionless & 3490.2 \\
Reynolds number $R e$ & Dimensionless & 119.8 \\
\hline
\end{tabular}

equivalent to a square well. One of the experimental conditions was chosen for comparison and the parameters used in the simulation are given in Table 4.

Fig. 9 shows the distribution of simulated and measured sand volume fraction with time in the fracture slots. It is obvious that the sand bed shape in the simulation is similar to that in the experiment. Due to the solid phase is assumed to be a continuous phase in the simulation, the shape of the sand bed is smoother compared to the experimental results. Fig. 10 shows the ratio of sand in the bypass to the total sand injected as a function of total amount of sand injected. The particle diameters were $0.4-0.8 \mathrm{~mm}$ in the experiment, while simplified uniform particle diameters $(0.6 \mathrm{~mm}$ and $0.7 \mathrm{~mm}$ ) were adopted in the simulation. The simulated results are close to the experimental values with a maximum deviation less than $23 \%$ when the particle diameter is $0.6 \mathrm{~mm}$, while the results are in good agreement with the experimental results when the particle diameter is $0.7 \mathrm{~mm}$. Apart from the simplified uniform particle diameters, the deviation between simulated and measured results may be caused by the simplified system geometry and the closed equations of solid phase. It is considered that the numerical simulation model used in this study is reliable with the allowable error.

\subsection{Effect of the bypass angle}

Figs. 11 and 12 show that the particles' transportation and deposition for bypass angles $45^{\circ}$ and $90^{\circ}$. At the initial stage of particles injecting into the main slot, the flow is similar to that in a single fracture. Once flowing to the intersections, particles accumulate in the main slot close to the intersections, then part of the accumulated particles are dragged into the branch slot progressively, while most of them continue to move straightly along the main slot. Fig. 13 shows that the particles deposit in the main and the front branch slot for case 1-4 (listed in Table 2 ) at different bypass angles of $10^{\circ}, 45^{\circ}, 60^{\circ}$ and $90^{\circ}$, respectively. Distribution range of particles in the branch slot decreases with the increase of the bypass angle, indicating that the particles can flow more easily into the branch slot at smaller bypass angles due to less loss of energy. The thickness of particle bed in the branch slot is larger than that in the main slot and increases with the increase of the bypass angle. The reason is that with the increase of the bypass angle, the velocity of water in the branch slot is become lower, leading to the particles' settlement and deposition.

The particle volume fraction in slots develops in three stages (Fig. 14): initially rapid increase, rapid decline, and stable status in the four bypass angles. A peak value appears at about 4-8 s. The particle volume fraction gets smaller and smaller with the bypass angle increases. The particles in the main slot are prone to accumulate at the leading-edge of the particle-laden flow path due to low viscosity of the particle-laden fluid and high density ratio of particle-to-liquid, leading to violent convection motion and deposition of particles. Owing to more particles' flow into the branch slot at smaller angle, the aggregation effects of particles are most pronounced when the bypass angle is $10^{\circ}$. In addition, particles concentration in the flow domain increases slightly with the increase of the bypass angle, and the characteristic time of reaching the stable flow status increases with the decrease of the bypass angle.

Mass flow rates in the branch and the main slot, represented by $\dot{m}_{\text {branch }}$ and $\dot{m}_{\text {main }}$, are compared to describe the capability of the particles entering into the branch slots at different angles. The cross sections of the branch and the main slots are shown in Fig. 15a. The mass flow rates in the branch and the main slots with bypass angles are shown in Fig. 15b. The results show that the percentage of the mass flow rate decreases with the increase of the angle, indicating that particles flow difficultly into the branch fracture with the bypass angle rising. The mass flow rate in the front branch is slightly greater than that in the rear branch.

\subsection{Effect of inlet particle volume fraction}

Fig. 16 shows the solid particles' deposition in the main and the front branch slot for cases 4, 8-10 at different inlet particle volume fractions. It is shown that the increase in the inlet particle volume fraction induces the quick deposition. With the increase of the volume fraction, the aggregation effects among particles become strong, accompanied by chain-like aggregation and deposition of particles. Richardson and Zaki (1954) proposed an empirical relationship of settling velocity of particle swarms, indicating the settling velocity decreases with the increase of particle concentration. The correlation is expressed as:

$v_{c}=\frac{\delta^{2} d_{\mathrm{s}}^{2}\left(\rho_{\mathrm{s}}-\rho_{\mathrm{l}}\right) g}{18 \mu_{\mathrm{l}}} \cdot 10^{-1.82(1-\delta)}$

where $\delta$ is the voidage and $v_{c}$ is the terminal settling velocity of particle swarms. The greater inlet particle volume fraction causes greater concentration difference at the leading-edge of the particle-laden liquid. Numerous particles gather at the leadingedge due to convection sedimentation at the initial stage, as shown in Figs. 17 and 18. It is noted that the length of the particle bed increases in an equivalent speed under different inlet volume fractions (Fig. 17). Fig. 18 shows the particle volume fraction in the flow domain of the slot increases with the increase of the inlet volume fraction at the stable stage. The inlet volume fraction has an important influence on the settling of particles. 
Branch slot

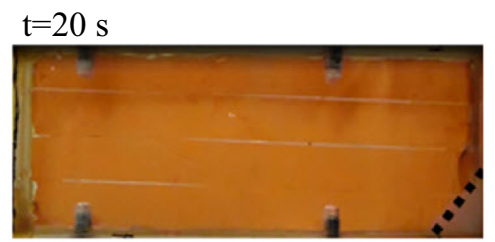

$\mathrm{t}=40 \mathrm{~s}$

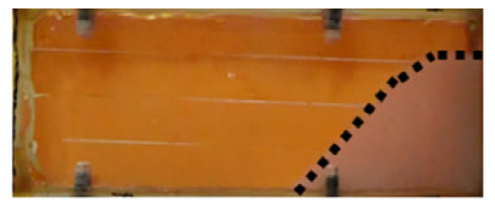

$\mathrm{t}=60 \mathrm{~s}$
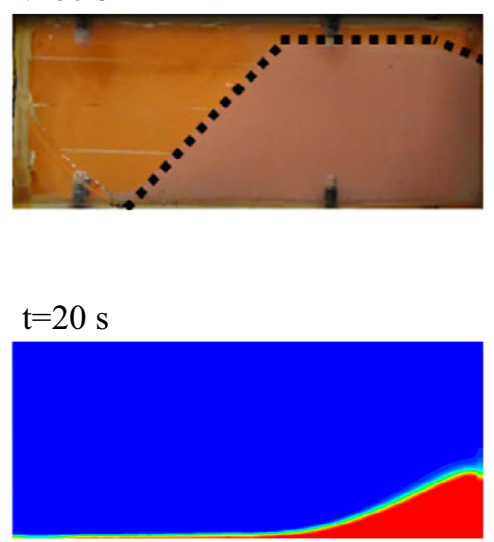

$\mathrm{t}=40 \mathrm{~s}$

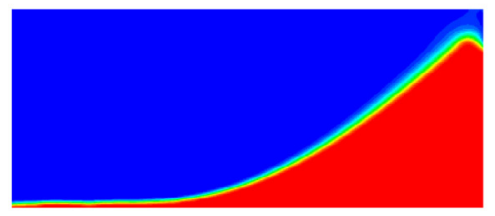

$\mathrm{t}=60 \mathrm{~s}$

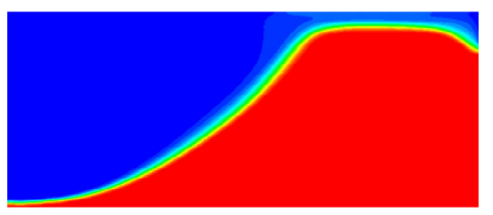

Main slot


(a)

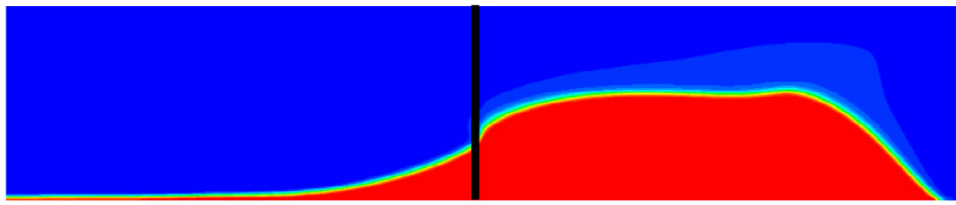

0.63

0.57

0.50

0.44

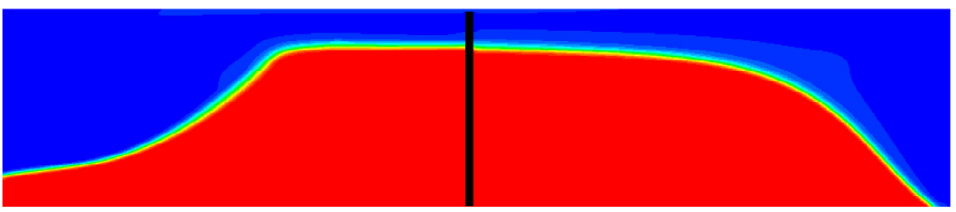

0.38

0.31

0.25

0.19

0.13

0.06

$\mathbf{0 . 0 0}$

(b)

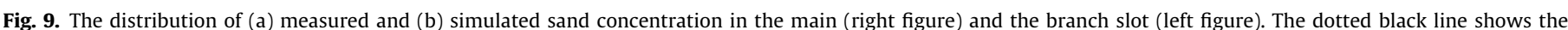

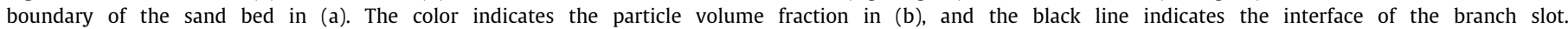

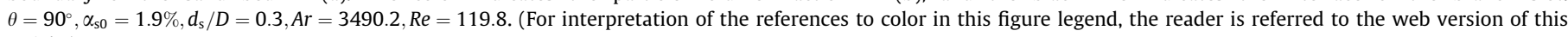
article.)

\subsection{Effect of $d_{\mathrm{s}} / w_{\mathrm{b}}$ (the ratio of particle size to branch slot width)}

The effects of the width of the branch slots on particles' deposition in cross fracture is investigated when the width of the main slot is kept constant. The bypass angle between the main slot and the branch slots is $45^{\circ}$, the width of the two branch slots is 3 $\mathrm{mm}, 4 \mathrm{~mm}, 5 \mathrm{~mm}$ and $6 \mathrm{~mm}$, respectively, hence $d_{s} / w_{\mathrm{b}}$ is 0.167 , $0.125,0.1$ and 0.083 , respectively.

Fig. 19 shows that particle volume fraction in the front branch slot at $1 \mathrm{~s}$ and $2 \mathrm{~s}$ when $d_{\mathrm{s}} / w_{\mathrm{b}}$ is $0.167,0.125,0.1$ and 0.083 , respectively. The movement length of the particles is the same, and more particles enter into the branch slot with the decrease of the ratio. 


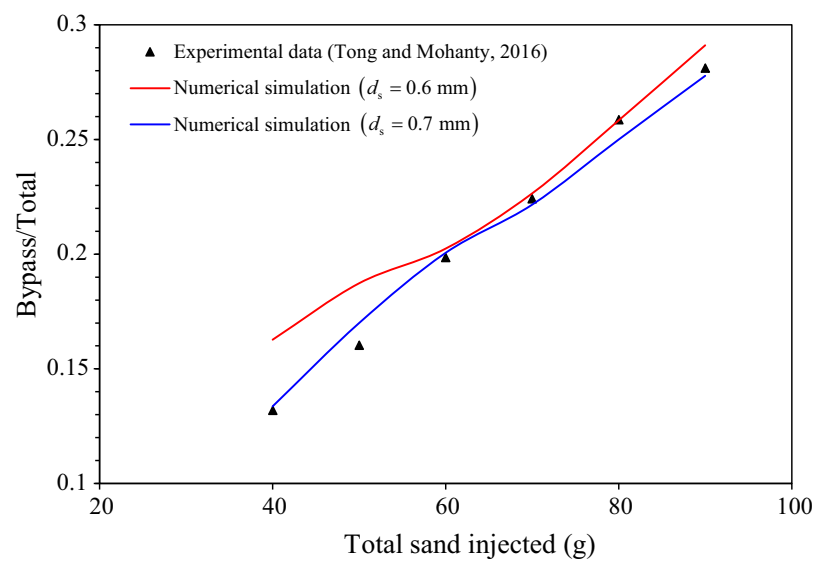

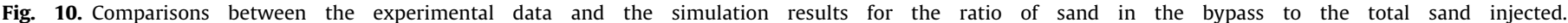
$\theta=90^{\circ}, \alpha_{\mathrm{s} 0}=1.9 \%, d_{\mathrm{s}} / D=0.3 / 0.35, A r=3490.2, \operatorname{Re}=119.8$.

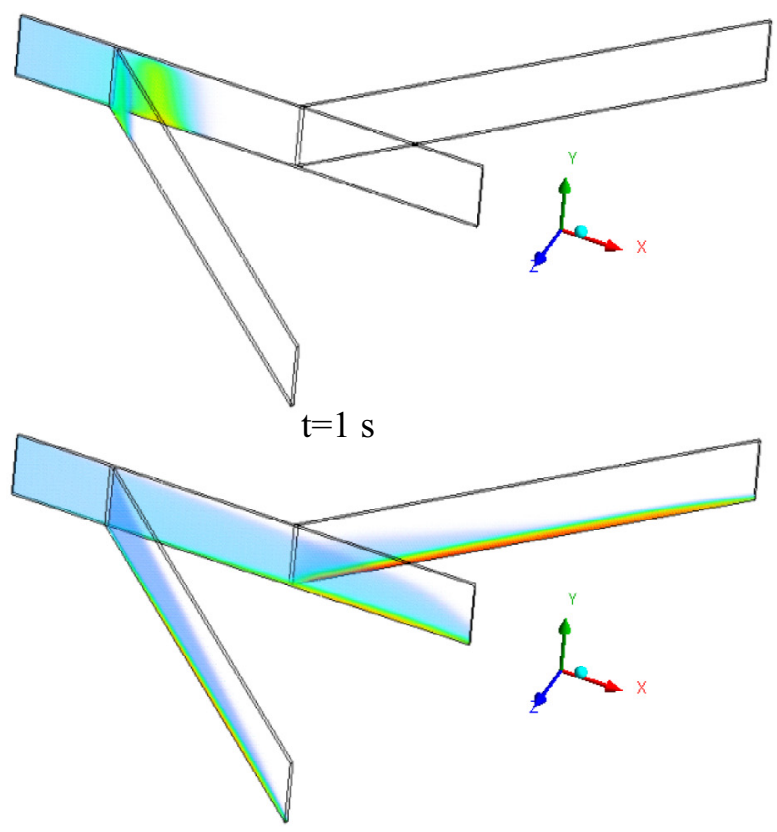

$\mathrm{t}=10 \mathrm{~s}$

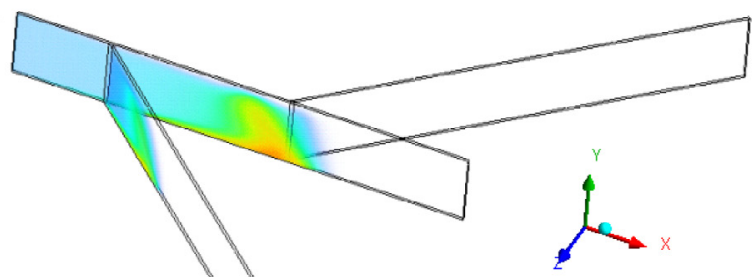

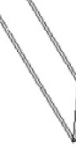

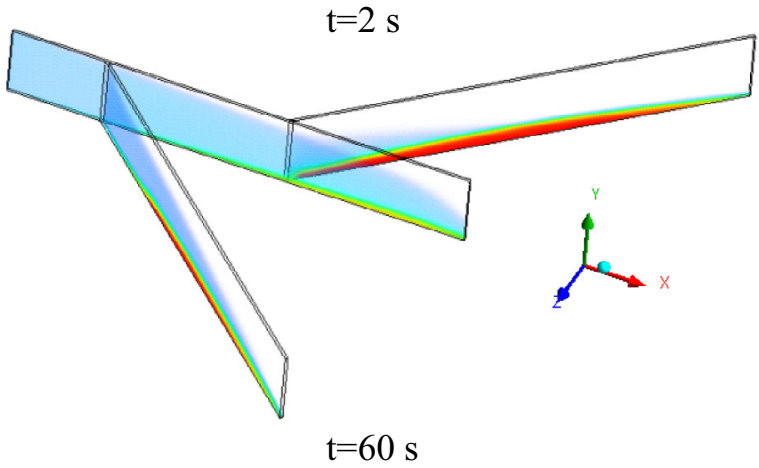

Volume fraction of particles

\begin{tabular}{lllll}
\hline & & & & \\
0 & 0.16 & 0.31 & 0.47 & 0.63
\end{tabular}

Fig. 11. Volume rendering of the volume fraction of particles at four times $1 \mathrm{~s}, 2 \mathrm{~s}, 10 \mathrm{~s}$ and $60 \mathrm{~s}$ with bypass angle $45^{\circ}, \alpha_{\mathrm{s} 0}=8 \%, d_{\mathrm{s}} / w_{\mathrm{b}}=0.083, A r=127.4, R e=100$.

The particle volume fraction in the entire slot is the largest for case 2 (the ratio is the smallest) when the system reaches a stable stage, as shown in Fig. 20. The time required for the system to reach the stable stage is also the largest for case 2, indicating that the twophase flow are capable of bring the particles to move further.

As shown in Fig. 21, the percentage of the mass flux decreases with the increase of the ratio of the particle size to the width of the branch slot. It is also found that the mass flux in the front branch is slightly greater than that of the rear branch.

\subsection{Effect of Ar and Re}

The particles enter into the slot, and move forward in the horizontal direction by drag force and settle in the vertical direction by gravity due to its larger density than liquid. The horizontal carrying capacity of the liquid can be characterized by the Reynolds number $R e_{\mathrm{s}}=\rho_{1} v_{0} d_{\mathrm{s}} / \mu_{\mathrm{l}}$ and the sedimentation effect of particles can be characterized by Archimedes number $A r=d_{\mathrm{s}}^{3} \rho_{\mathrm{l}}\left(\rho_{\mathrm{s}}-\rho_{\mathrm{l}}\right) g / \mu_{\mathrm{l}}^{2}$ (Li et al., 2017). Here, a new dimensionless 




$\mathrm{t}=1 \mathrm{~s}$



$\mathrm{t}=10 \mathrm{~s}$

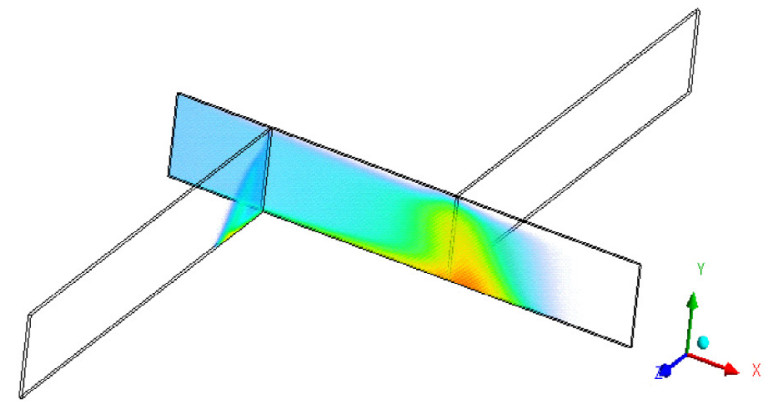

$\mathrm{t}=2 \mathrm{~s}$

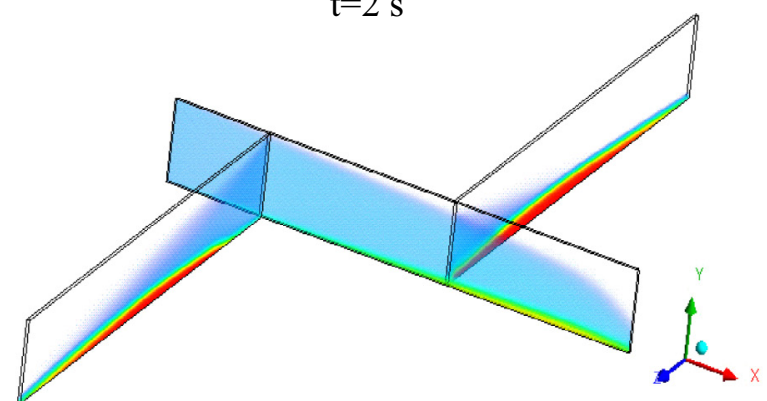

$\mathrm{t}=60 \mathrm{~s}$

Volume fraction of particles
\begin{tabular}{|lllll}
\hline & & & & \\
0 & 0.16 & 0.31 & 0.47 & 0.63
\end{tabular}

Fig. 12. Volume rendering of the volume fraction of particles at four times $1 \mathrm{~s}, 2 \mathrm{~s}, 10 \mathrm{~s}$ and $60 \mathrm{~s}$ with bypass angle $90^{\circ}, \alpha_{\mathrm{s} 0}=8 \%, d_{\mathrm{s}} / w_{\mathrm{b}}=0.083, A r=127.4, R e=100$.

Case 1: $\theta=10^{\circ}$

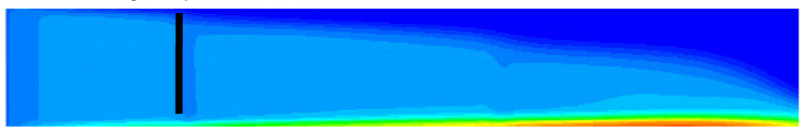

Case 2: $\theta=45^{\circ}$



Case 3: $\theta=60^{\circ}$

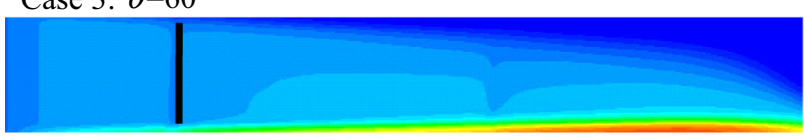

Case 4: $\theta=90^{\circ}$

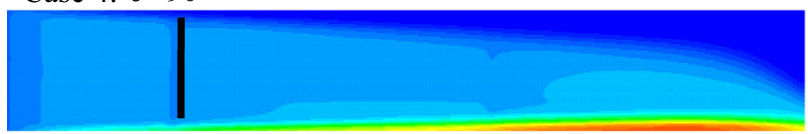

the main slot
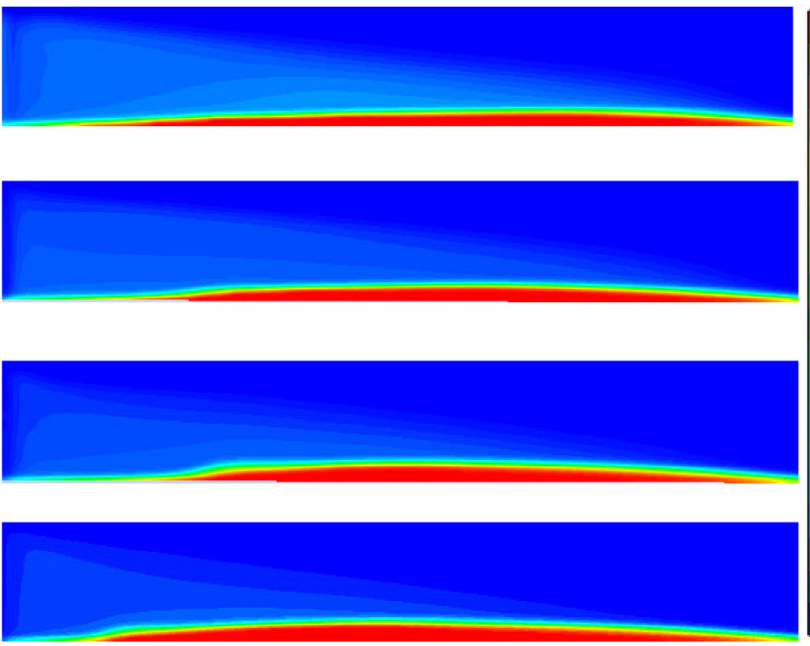

the front branch slot

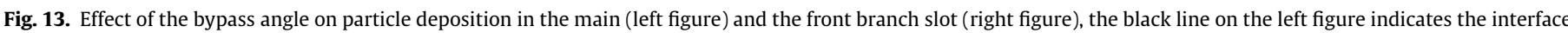
of the front branch slot, the color indicates particle volume fraction. $\alpha_{\mathrm{s} 0}=8 \%, d_{\mathrm{s}} / w_{\mathrm{b}}=0.083, A r=127.4, \operatorname{Re}=100, t=60 \mathrm{~s}$.

number is presented as the ratio of the Reynolds number and the Archimedes number, representing the relative magnitude of the liquid carrying capacity to the particles sedimentation effects. It can be expressed as:

$\Pi=\frac{\operatorname{Re}_{\mathrm{s}}}{A r}=\frac{v_{0} \mu_{1}}{d_{\mathrm{s}}^{2}\left(\rho_{\mathrm{s}}-\rho_{\mathrm{l}}\right) g}$
According to Eq. (35), the greater the velocity and viscosity of the liquid, the larger the particle bed length. With the increase of the diameter of particles and the density difference between the two phases, the particles' sedimentation becomes more violent. As in Fig. 22a, the velocity of the liquid in the branch slot is lower than that in the main slot while the liquid velocity in the rear branch slot is lower than that in the front branch slot due to energy 


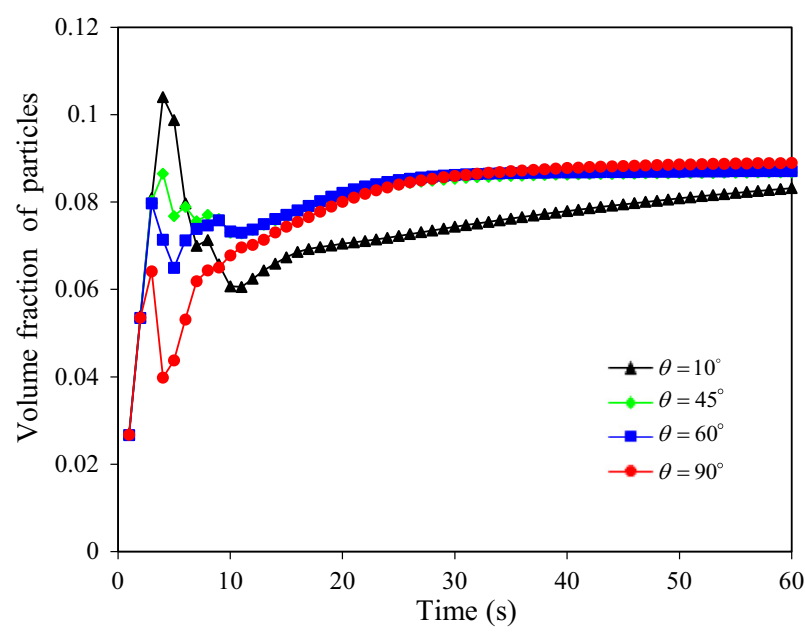

Fig. 14. Volume fraction of particles in whole slot with time in cross fractures for case $1-4$ (listed in Table 1$), \alpha_{\mathrm{s} 0}=8 \%, d_{\mathrm{s}} / w_{\mathrm{b}}=0.083, A r=127.4, \operatorname{Re}=100$.

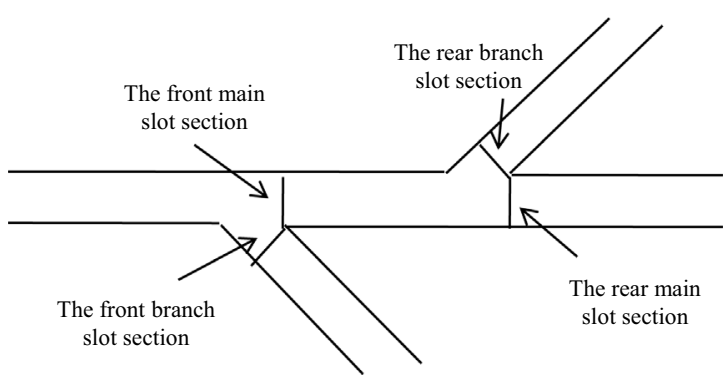

(a)

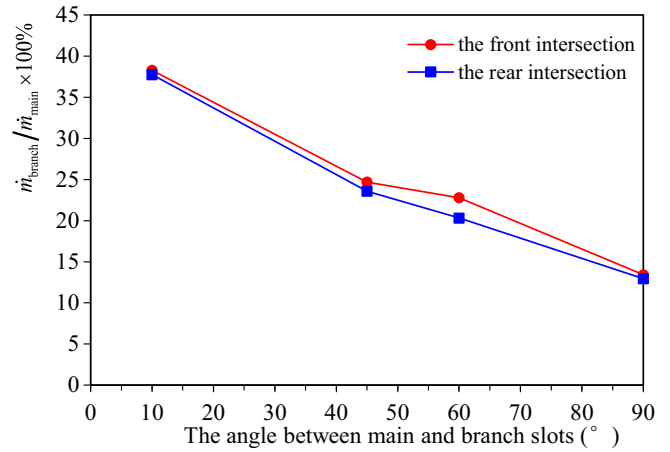

(b)

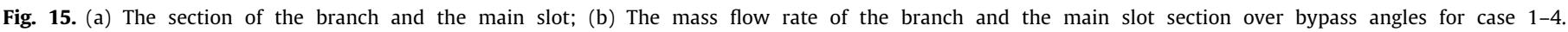
$\alpha_{\mathrm{s} 0}=8 \%, d_{\mathrm{s}} / w_{\mathrm{b}}=0.083, A r=127.4, \operatorname{Re}=100, t=60 \mathrm{~s}$.

Case 8: $\alpha_{\mathrm{s} 0}=2.7 \%$
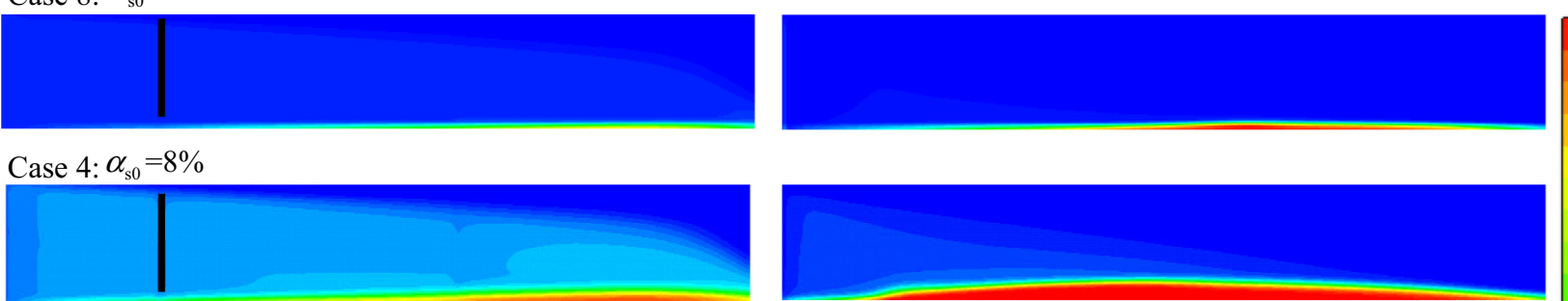

Case 4: $\alpha_{\mathrm{s} 0}=8 \%$
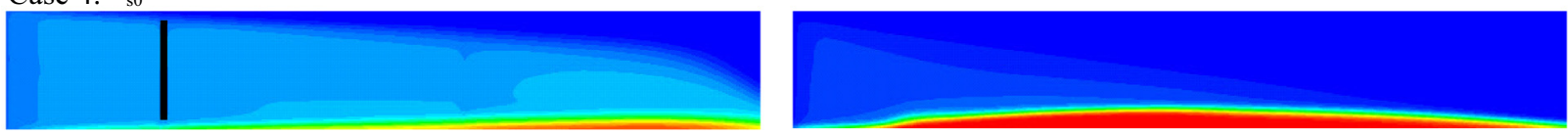

Case 9: $\alpha_{\mathrm{s} 0}=13 \%$
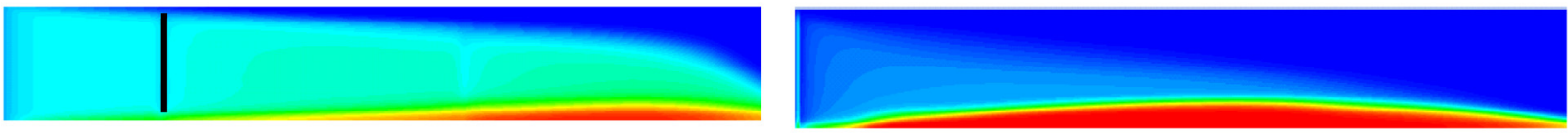

Case 10: $\alpha_{\mathrm{s} 0}=18 \%$

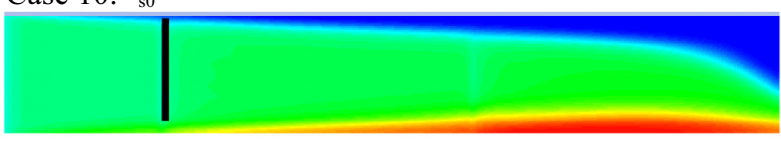

the main slot

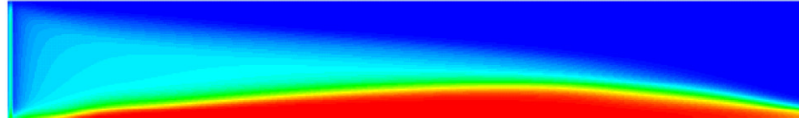

the front branch slot

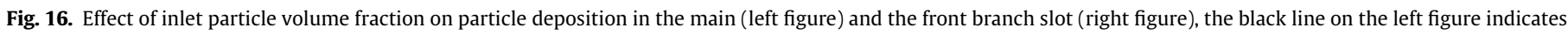

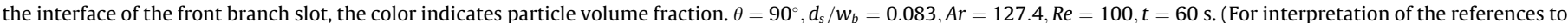
color in this figure legend, the reader is referred to the web version of this article.) 


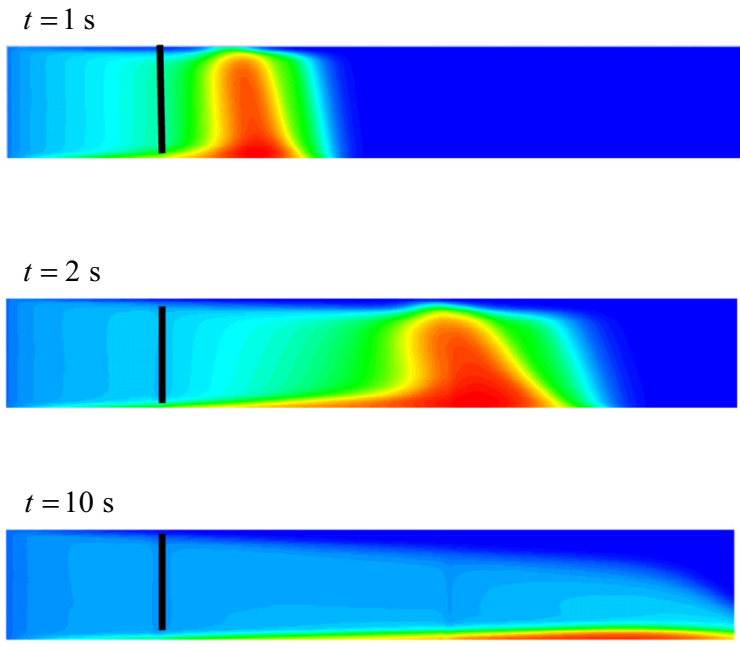

the main slot
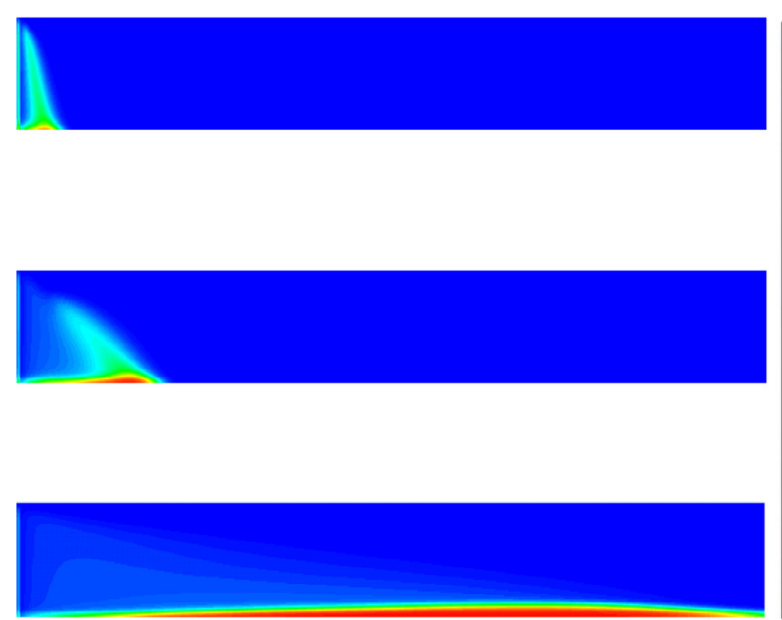

the front branch slot

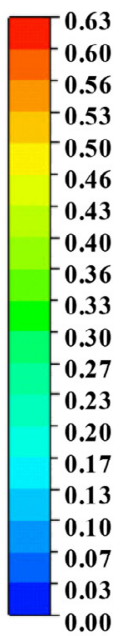

0.00

(a) $\alpha_{\mathrm{s} 0}=8 \%$
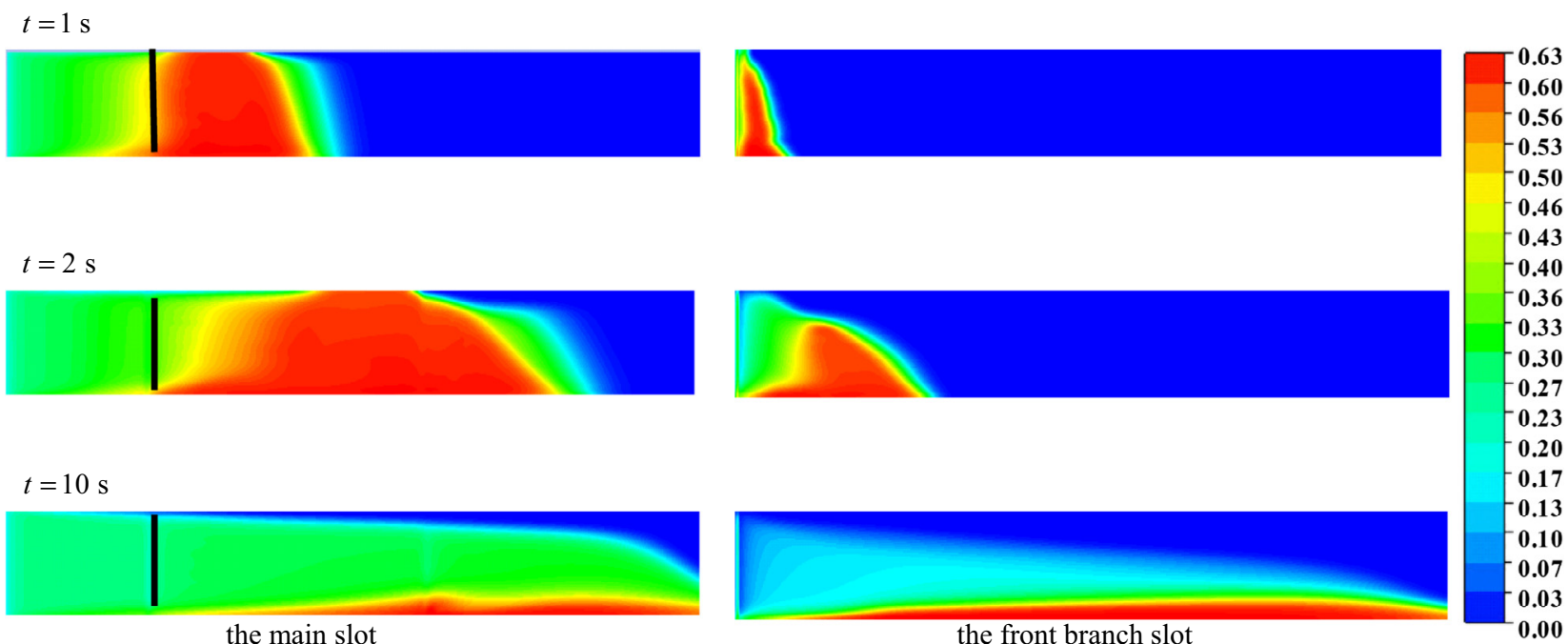

$t=2 \mathrm{~s}$
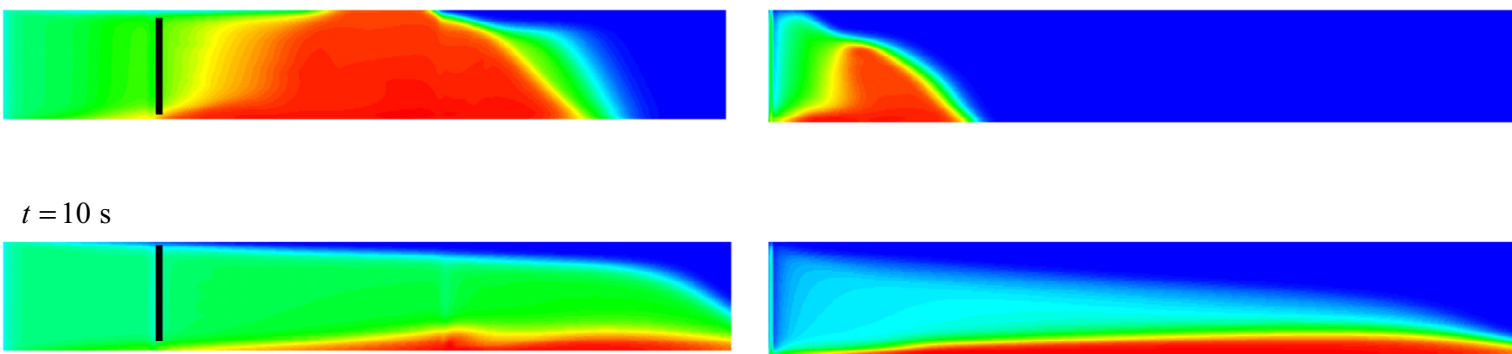

the main slot

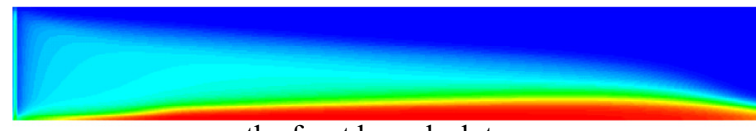

the front branch slot

(b) $\alpha_{\mathrm{s} 0}=18 \%$

Fig. 17. Contours of volume fraction of particles in the main slot (left figure) and the front branch slot (right figure) at three times $1 \mathrm{~s}, 2 \mathrm{~s}$ and $10 \mathrm{~s}$ under different inlet particle volume fraction. (a) $8 \%$ and (b) $18 \%$. The black line on the left figure indicates the interface of the front branch slot, the color indicates particle volume fraction $\theta=90^{\circ}, d_{s} / w_{b}=0.083, A r=127.4, R e=100, t=60 \mathrm{~s}$. (For interpretation of the references to color in this figure legend, the reader is referred to the web version of this article.)



Fig. 18. Volume fraction of particles in whole slot with time in cross fractures for cases $8,4,9$ and $10, \theta=90^{\circ}, d_{\mathrm{s}} / w_{\mathrm{b}}=0.083, A r=127.4, R e=100$. 
Case 5: $d_{\mathrm{s}} / w_{\mathrm{b}}=0.167$
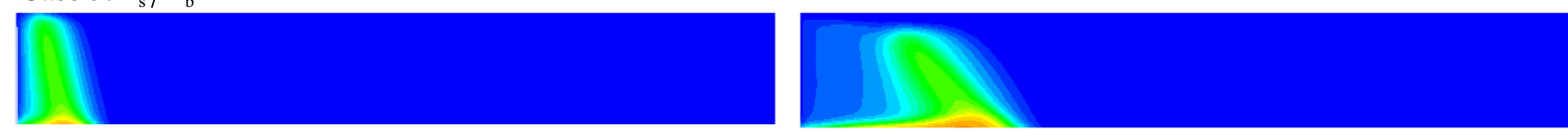

Case 6: $d_{\mathrm{s}} / w_{\mathrm{b}}=0.125$
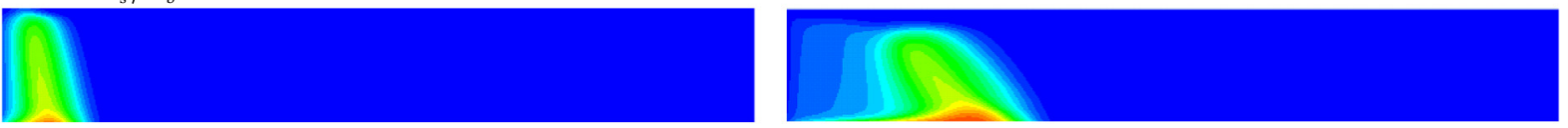

Case 7: $d_{\mathrm{s}} / w_{\mathrm{b}}=0.1$
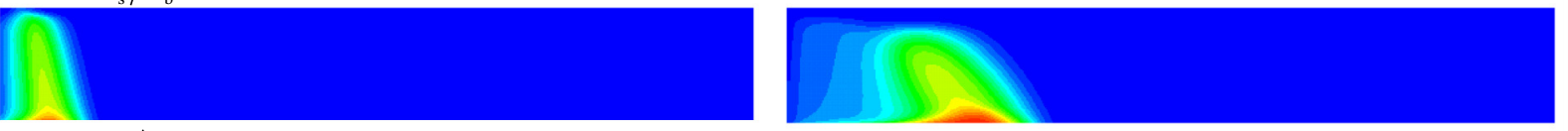

Case $2: d_{\mathrm{s}} / w_{\mathrm{b}}=0.083$

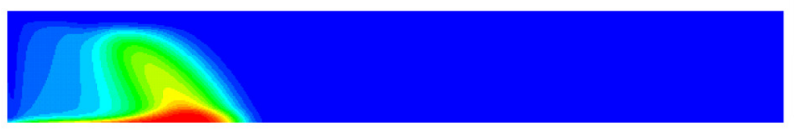

$t=2 \mathrm{~s}$

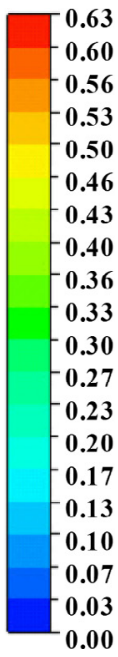

$$
t=1 \mathrm{~s}
$$

Fig. 19. Contours of volume fraction of particles in the front branch slot for cases $5,6,7$ and 2 at $\mathrm{t}=1 \mathrm{~s}$ (left figure) and $\mathrm{t}=2 \mathrm{~s}$ (right figure). The color indicates particle volume fraction. $\theta=45^{\circ}, \alpha_{s 0}=8 \%, A r=127.4, R e=100$. (For interpretation of the references to color in this figure legend, the reader is referred to the web version of this article.)

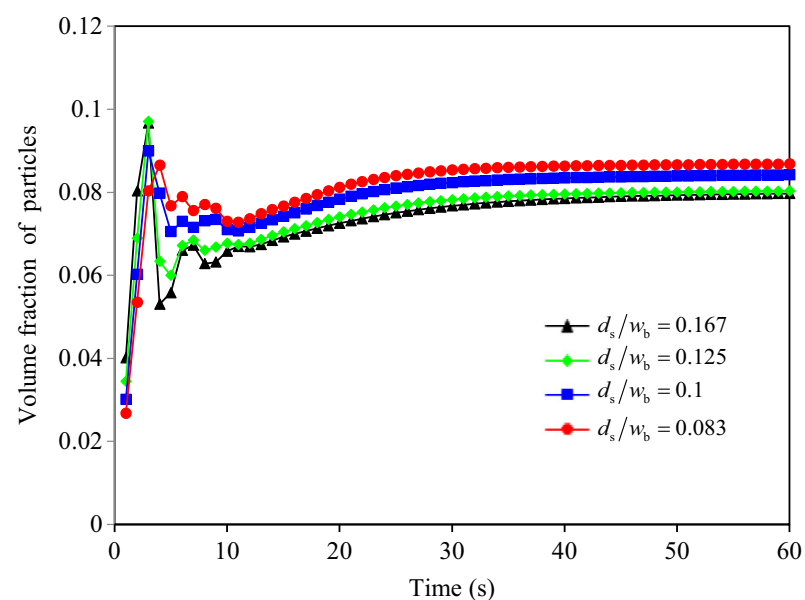

Fig. 20. Volume fraction of particles in the whole slot with time in cross plate for cases $5,6,7$ and $2, \theta=45^{\circ}, \alpha_{\mathrm{s} 0}=8 \%, A r=127.4, \operatorname{Re}=100$.

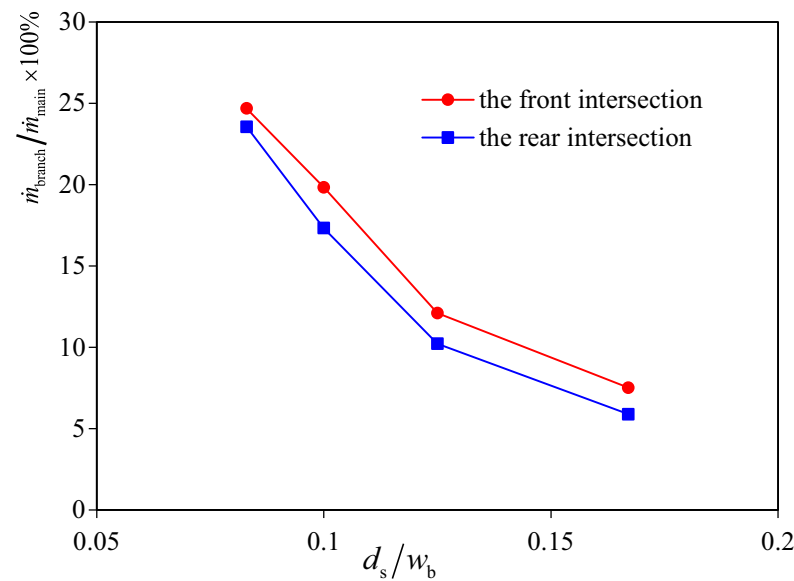


$2, \theta=45^{\circ}, \alpha_{\mathrm{s} 0}=8 \%, A r=127.4, \operatorname{Re}=100, t=60 \mathrm{~s} .$. 


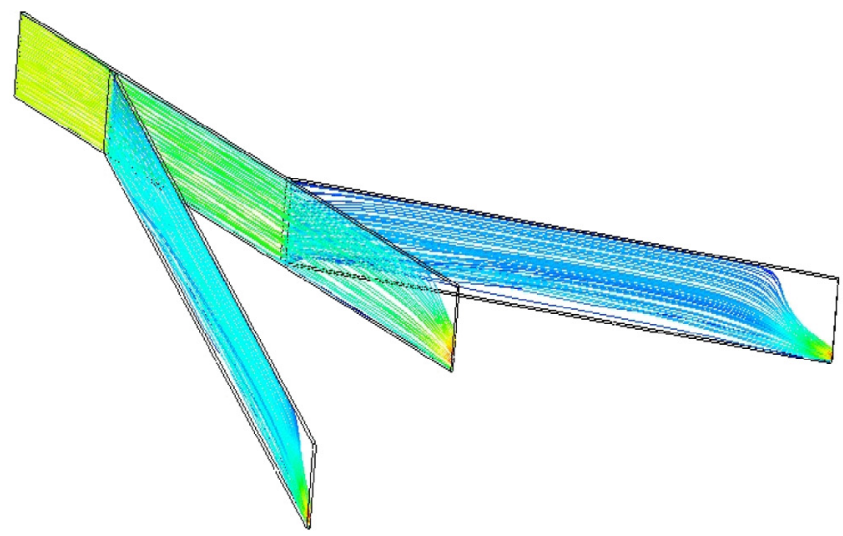

(a)

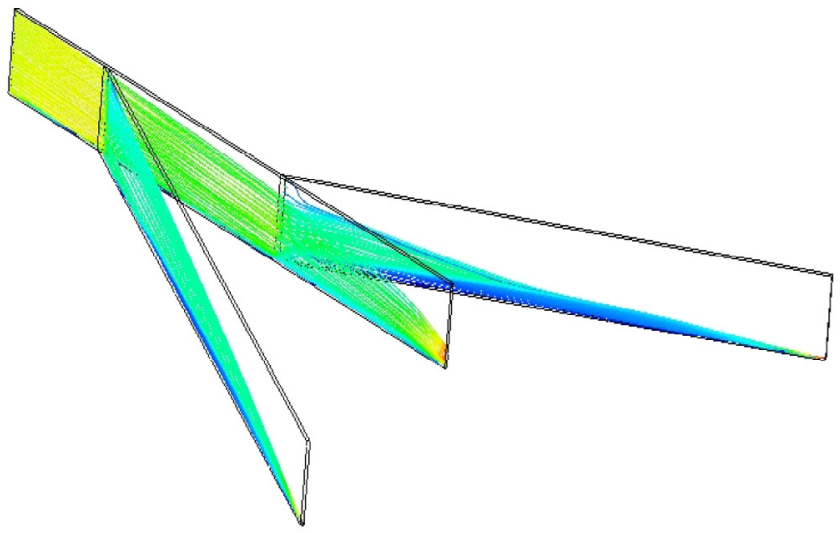

(b)

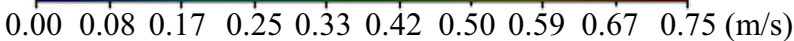

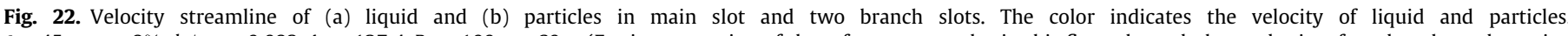

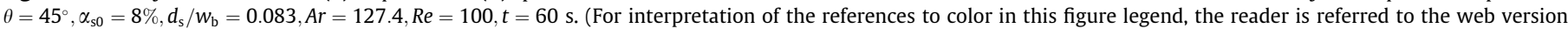
of this article.)

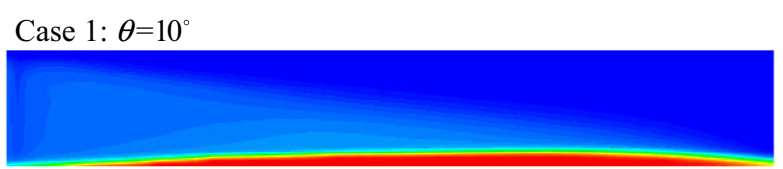

Case 2: $\theta=45^{\circ}$

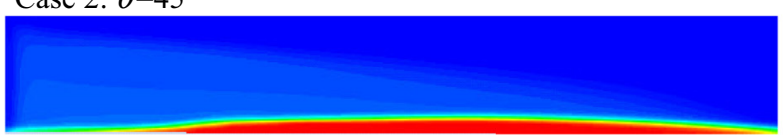

Case 3: $\theta=60^{\circ}$

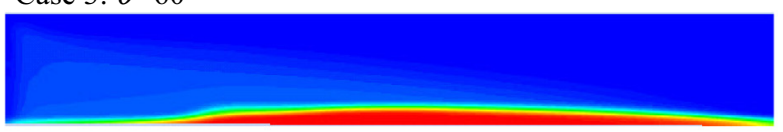

Case 4: $\theta=90^{\circ}$

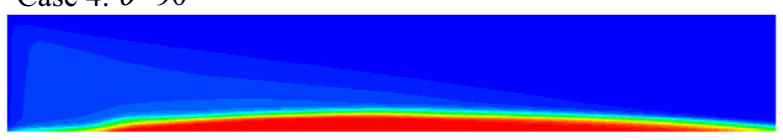

the front branch slot

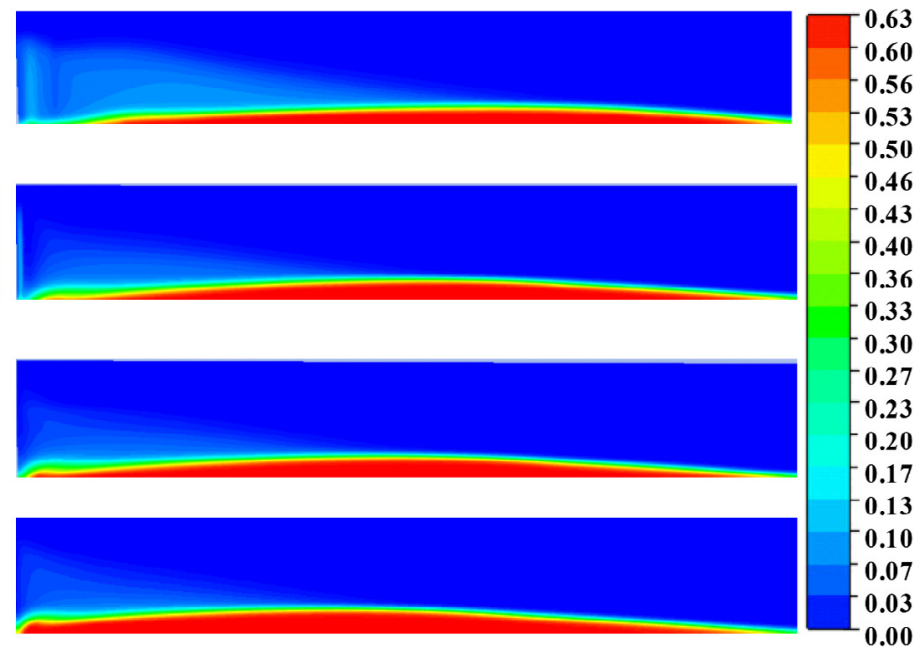

the rear branch slot



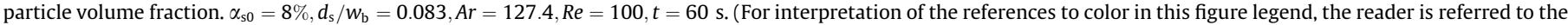
web version of this article.)

dissipation. It can be inferred that the carrying capacity of the liquid in the front branch slot is better than that in the rear branch slot. The mass flux at the front branch entry is slightly greater than that at the rear branch entry as shown in Figs. 15b and 21. The velocity of the liquid in the rear branch slot becomes lower and the dimensionless number becomes smaller, leading to more particles settling on the bottom of the slot, as shown in Fig. 22b. The rear branch slot is more distant from the inlet, and increases the horizontal move length of the particles, hence the particle volume fraction in the rear branch slot is greater than that in the front branch slot when the system is stable as in Fig. 23. The carrying capacity of the liquid progressively increases and the thickness of the particle bed in the slot decreases with the increase of dimensionless number $\Pi$, as shown in Fig. 24. This phenomenon can be explained by the effect of the dimensionless number on the mass flow rates in the branch and the main slots. As can be seen in Fig. 25, the percentage of the mass flow rate decreases with the increase of the dimensionless number $\Pi$. The simulated results indicate that the particles are more difficult to enter the branch slot as the dimensionless number increases. 


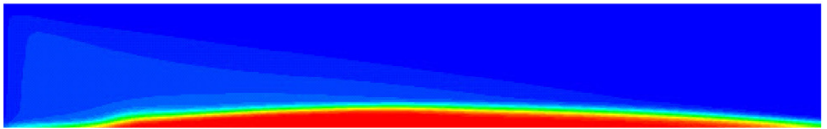

Case 4: $\Pi=0.785(\operatorname{Re}=100, A r=127.4)$

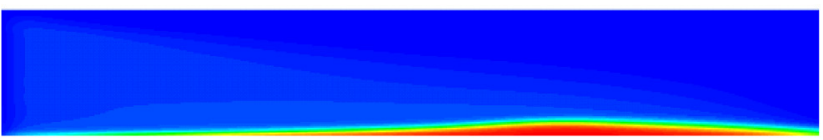

Case 11: $\Pi=1.177(\operatorname{Re}=150, A r=127.4)$

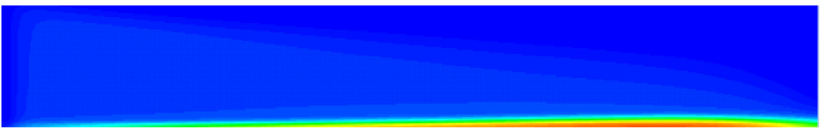

Case $12: \Pi=1.570(\operatorname{Re}=200, A r=127.4)$

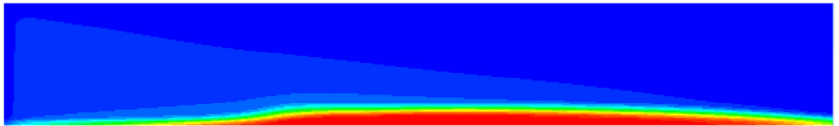

Case 14: $\Pi=0.993(\operatorname{Re}=100, A r=100.7)$

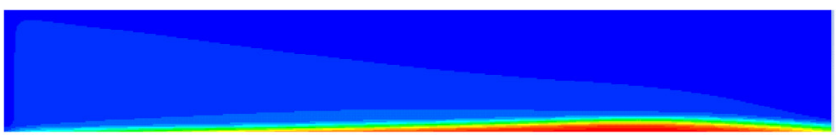

Case $15: \Pi=1.297(R e=100, A r=77.1)$

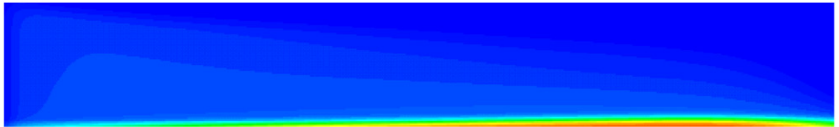

Case 16: $\Pi=1.767(\operatorname{Re}=100, A r=56.6)$

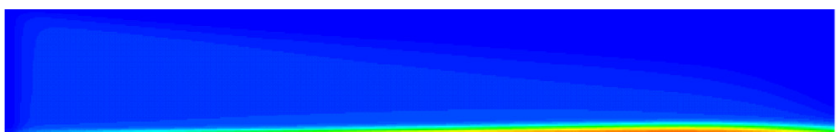

Case 13: $\Pi=2.355(\operatorname{Re}=300, A r=127.4)$

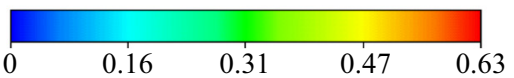

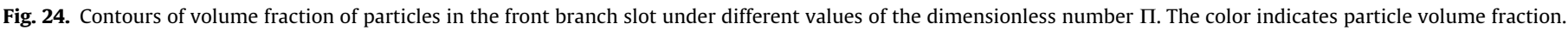
$\theta=90^{\circ}, \alpha_{\mathrm{s} 0}=8 \%, d_{\mathrm{s}} / w_{\mathrm{b}}=0.083, t=60 \mathrm{~s}$. (For interpretation of the references to color in this figure legend, the reader is referred to the web version of this article.)

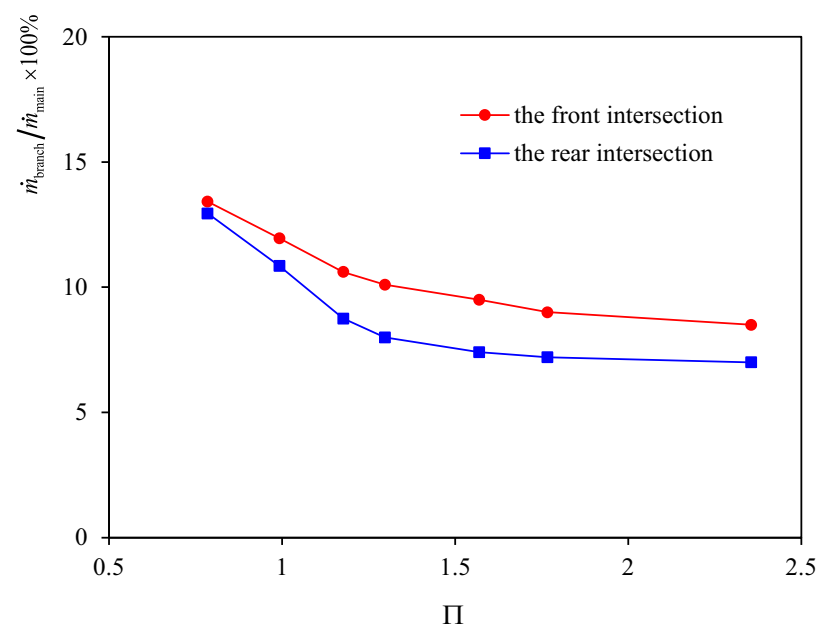

Fig. 25. The mass flow rate of the branch slot and the main slot section with the dimensionless number П. $\theta=90^{\circ}, \alpha_{\mathrm{s} 0}=8 \%, d_{\mathrm{s}} / w_{\mathrm{b}}=0.083, t=60 \mathrm{~s}$.

\section{Conclusion}

In this paper, a Eulerian-Eulerian method (i.e., two-fluid model) is used to study solid-liquid two-phase flow in cross fractures. The cross fractures consist of one main slot and two branch slots. The bypass angle is varied from $10^{\circ}$ to $90^{\circ}$, the width of the branch slot ranges from $3 \mathrm{~mm}$ to $6 \mathrm{~mm}$. The effect of the slot's geometry, particle properties, fluid properties and boundary conditions on solid-liquid two-phase flow is analyzed and discussed. Based on Buckingham pi theorem, eight dimensionless numbers are derived to understand the particles' transportation and deposition in the cross fractures, including $\theta, \alpha_{\mathrm{s} 0}, d_{\mathrm{s}} / w_{\mathrm{m}}, d_{\mathrm{s}} / w_{\mathrm{b}}, d_{\mathrm{s}} / H, d_{\mathrm{s}} / L_{\mathrm{s}}, \rho^{*}, R e$,
$A r$. Sensitivity analysis is performed on $\theta, \alpha_{\mathrm{s} 0}, d_{\mathrm{s}} / w_{\mathrm{b}}, \rho^{*}, \operatorname{Re}, A r$, keeping other numbers constant.

Some salient features are captured by the numerical simulations as:

The bypass angle plays a dominant role in the transportation of the particles in cross fractures. The increase of the bypass angle reduces the particles' mass flow into the branch slot. Particles' deposition in the branch slot decreases with the increase of the bypass angle, while the thickness of particle bed increases with the increase of the bypass angle.

As the inlet particle volume fraction increases, the aggregation effect between particles becomes more violent, as well as the particles' settling velocity decreases, resulting in quick particle deposition in both main and branch slots. The decrease of the width of the branch slot reduces the number of particles entering into the branch slot.

$\mathrm{Re}$ and $\mathrm{Ar}$ are of great importance to solid-liquid two-phase flow in cross fractures. The liquid's drag force increase with the increase of $R e$, and more particles' deposition in the fractures occurs with the increase of $A r$, leading to more particles entering into the front branch fracture. A new dimensionless number $\Pi$ (the ratio of the Reynolds number and the Archimedes number) is presented, and can clearly describe relative magnitude of the liquid's carrying capacity to the particles' sedimentation effect.

\section{Acknowledgments}

This research was supported by the Foundation of State Key Laboratory of Shale Oil and Gas Enrichment Mechanisms and Effective Development (Grant No. G5800-15-ZS-WX047), the National Science and Technology Major Project of China (Grant No. 
2016ZX05046-003-002-001), and the Youth Innovation Promotion Association CAS (2017027).

\section{References}

Askaripour, H., Dehkordi, A.M., 2016. Effects of initial static bed height on fractional conversion and bed pressure drop in tapered-in and tapered-out fluidized bed reactors. Int. J. Multiph. Flow 79, 50-61.

Babcock, R.E., Prokop, C.L., Kehle, R.O., 1967. Distribution of propping agents in vertical fractures. Am. Pet. Inst. Publ., United States, pp. 851-41-a.

Cornelissen, J.T., Taghipour, F., Escudié, R., Ellis, N., Grace, J.R., 2007. CFD modelling of a liquid-solid fluidized bed. Chem. Eng. Sci. 62 (22), 6334-6348.

Ding, J., Gidaspow, D.A., 1990. Bubbling fluidization model using kinetic theory of granular flow. Aiche J. 36 (4), 523-538.

Gidaspow, D., Bezburuah, R., Ding, J., 1992. Hydrodynamics of circulating fluidized beds: kinetic theory approach. In: Proceedings of the 7th Engineering Foundation Conference on Fluidization, pp. 75-82.

Gidaspow, D., 1994. Multiphase Flow and Fluidization: Continuum and Kinetic Theory Descriptions. Academic press, San Dieg o.

Jackson, R., 1997. Locally averaged equations of motion for a mixture of identical spherical particles and a Newtonian fluid. Chem. Eng. Sci. 52, 2457-2469.

Johnson, P.C., Jackson, R., 1987. Frictional-collisional constitutive relations for granular materials, with application to plane shearing. J. Fluid Mech. 176, 67-93.

Kaushal, D.R., Thinglas, T., Tomita, Y., Tomita, Y., Kuchii, S., Tsukamoto, H., 2012. CFD modeling for pipeline flow of fine particles at high concentration. Int. J. Multiph. Flow 43, 85-100.

Kern, K., Perkins, T.K., Wyant, R.E., 1959. The mechanics of sand movement in Fracturing. J. Petrol. Technol. 11 (7), 55-57.

Kuwagi, K., Kogane, A., Hirano, H., Alias, A.B., Takami, T., 2014. Nondimensionalization and three-dimensional flow regime map for fluidization analyses. Chem. Eng. Sci. 119 (6), 199-211.

Lanuder, B.E., Spalding, D.B., 1974. The numerical computation of turbulent flows. Comput. Methods Appl. Mech. Eng. 3, 269-289.

Li, P., Su, J., Zhang, Y., Zhang, X., Lu, X., 2017. The two phase flow of proppant-laden fluid in a single fracture. Mech. Eng. 39 (2), 135-144.
Lun, C.K.K., Savage, S.B., Jeffrey, D.J., Chepurniy, N., 1984. Kinetic theories for granular flow: inelastic particles in Couette flow and slightly inelastic particles in a general flow field. J. Fluid Mech. 140 (140), 223-256.

Manoorkar, S., Sedes, O., Morris, J.F., 2016. Particle transport in laboratory models of bifurcating fractures. J. Nat. Gas Sci. Eng. 33, 1169-1180.

Ogawa, S., Umemura, A., Oshima, N., 1980. On the equations of fully fluidized granular materials. Zeitschrift für angewandte Mathematik und Physik. 31 (4) 483-493.

Orszag, S.A., Yakhot, V., Flannery, W.S., Boysan, F., Choudhury, D., Maruzewski, J., Patel, B., 1993. International Conference on Near-Wall Turbulent Flows, pp. 1031-1046.

Richardson, J.F., Zaki, W.N., 1954. Sedimentation and fluidization. Part I Trans. Institut. Chem. Eng. 32, 35-53.

Sahai, R., Miskimins, J.L., Olson, K.E., 2014. Laboratory results of proppant transport in complex fracture systems. Soc. Petrol. Eng. 168579.

Shiozawa, S., Mcclure, M., 2016. Simulation of proppant transport with gravitational settling and fracture closure in a three-dimensional hydraulic fracturing simulator. J. Petrol. Sci. Eng. 138, 298-314.

Syamlal, M., Rogers, W., O‘Brien, T.J., 1993. MFIX Documentation Theory Guide. National Technical Information Service, Springfield, United States.

Tan, Q.M., 2011. Dimensional Analysis: with Case Studies in Mechanics. Springer Verlag, Berlin, Heidelberg.

Tong, S., Mohanty, K.K., 2016. Proppant transport study in fractures with intersections. Fuel 181, 463-477.

Tsai, K., Degaleesan, S.S., Fonseca, E.R., Lake, E., 2012. Advanced computational modeling of proppant settling in water fractures for shale gas production. Spe J. 18 (1), 1389-1394. https://doi.org/10.2118/151607-PA

Wang, J., Joseph, D.D., Patankar, N.A., Conway, M., Barree, R.D., 2003. Bi-power law correlations for sediment transport in pressure driven channel flows. Int. J. Multiph. Flow 29 (3), 475-494.

Zeng, J., Li, H., Zhang, D., 2016. Numerical simulation of proppant transport in hydraulic fracture with the upscaling CFD-DEM method. J. Nat. Gas Sci. Eng. 33, 264-277.

Zhong, W., Yu, A., Zhou, G., Xie, J., 2016. CFD simulation of dense particulate reaction system: Approaches, recent advances and applications. Chem. Eng. Sci. 140 (50), 16-43. 